\title{
Ecosystem
} Health and Sustainable Agriculture
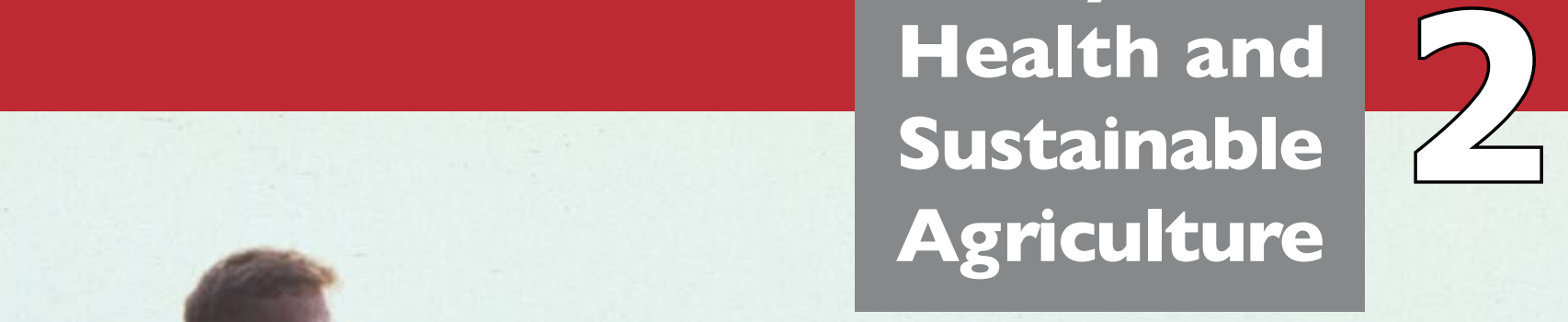

$$
\text { (n) }
$$

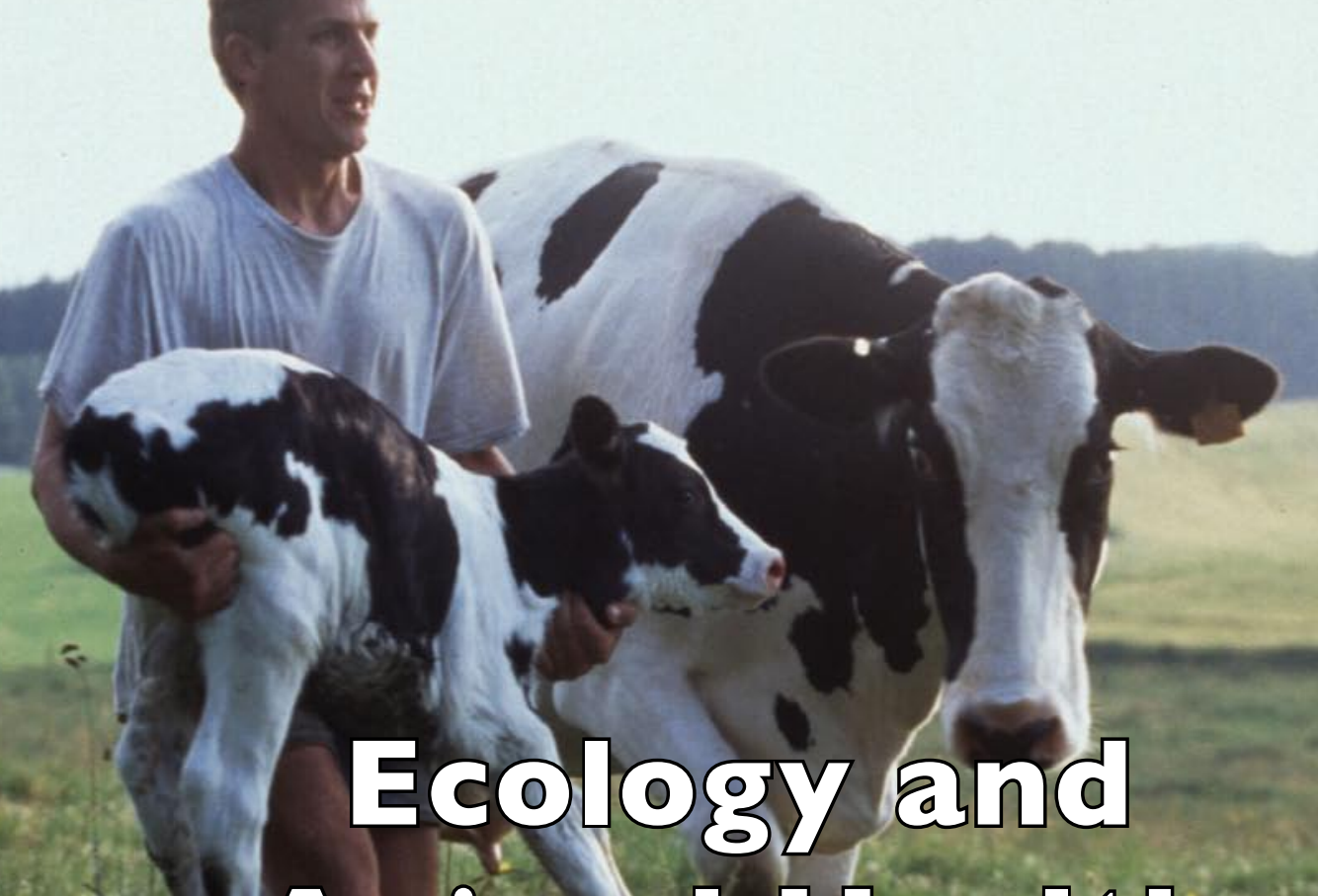




\section{Preparing for Climate Change}

Climate change (CC) in terms of global warming and sea level rise is an ongoing process and a topic of immediate interest. Extreme weather events such as heat waves, storms, heavy precipitation, floods and droughts, are expected to become more frequent as $\mathrm{CC}$ progresses; whereas snow cover and the coverage of land and sea ice are predicted to contract. According to a report from the UN Intergovernmental Panel (IPCC, 2007) the main underlying reason for $\mathrm{CC}$ is anthropogenic greenhouse gas emissions causing a global increase in average temperatures. Even though this report is based on a huge amount of scientific evidence, it has been criticised for underestimating certain effects of $\mathrm{CC}$, such as the extent of loss of Arctic and Antarctic ice-cover. A recent Swedish review of scientific literature published 2007-2009 concluded that continued global warming is more severe than previously thought and that future effects can be even more far-reaching than previously estimated (Rummukainen and Källén, 2009).

The mathematical modelling of predicted $\mathrm{CC}$ is becoming increasingly advanced and the possibility to assess changes in the future climate is improving continuously. However, climate models, just as any other kind of mathematical models, have their limitations considering the possible amount of parameters included and their interactions and flexibility. Therefore any predictions of $\mathrm{CC}$ should be considered indicative rather than accurate.

Depending on the viewpoint, $\mathrm{CC}$ may cause positive effects for certain regions and species, for example for crop production in some regions. However, in general, as a consequence of $\mathrm{CC}$, many severe problems for society and agricultural production are expected to surface or, in some cases, are already evident (SOU, 2007:60). Increased shortage of water is anticipated to become an increasing problem for society. As CC influences health in many ways, the well-being of humans and domestic animals as well as of wildlife and ecosystems is expected to be affected. In the case of extreme weather events the health effects may be drastic and acute. Other effects from extreme weather events are that lack of feed and water may follow or there may be outbreaks of epizootic disease. Heat stress may cause suppressed production and decreased reproductive performance in farm animals (Sartori et al., 2002; Huynh et al., 2005). The impact of vector-borne diseases (VBD) that are transmitted between individuals via insect or other arthropod vectors on human and animal health is expected to increase. Several of these VDB are zoonoses and can therefore be transmitted between humans and animals (for example West 
Nile fever and Lyme borreliosis); others involve a severe impact 'only' for animal husbandry (for example blue tongue disease).

Mitigation of the above-mentioned effects is central in today's discussion of $\mathrm{CC}$, but adaptations and animal health effects would benefit from greater attention. For example heat stress among domestic animals may be less severe in temperate climate zones if animal breeds genetically adapted to a warmer climate are used (Setchell, 2006) and if farmhouses are constructed in a way that protects animals from high temperatures and humidity. However, adaptations to protect for infectious diseases, which often appear as a surprise in new regions, may be rather difficult to achieve, and prediction and response to future problems is demanding. To understand and facilitate adaptation to $\mathrm{CC}$ - as far as possible - increased knowledge is needed about changes in ecosystems, including interactions between vector animals, wildlife, domestic animals and humans. For certain diseases vaccination of a population of animals or humans may be an alternative when the risk of introduction of a new disease is high or when the disease has already been introduced. However, effective vaccines are not always available or affordable. Vaccination of livestock in northern Europe against blue tongue disease has been extensive since the disease was introduced in 2006 (Purse et al., 2008).

\section{Potential for Animal Production will Change}

Today's agriculture is under high pressure to increase its productivity, which would compensate for food scarcities and an increasing human population (FAO, 2008). At the same time there is a demand for the negative impacts of agricultural production on the environment to decrease (Steinfeldt et al., 2006). This is a global dilemma of the highest priority which has yet to be solved. Healthy animals are a key factor in this regard, since they produce more food while consuming less feed (Wood and Lysons, 1988). In addition, healthy animals cause less greenhouse gas emissions in proportion to the amount of food produced (Flint and Woolliams, 2008). Even so, if the main purpose of agriculture is food production, it should not be forgotten that animal production includes promoting sustainable rural development and preservation of biodiversity and ecosystem health.

Climatic changes are expected to alter the potential for farming and animal production, but the consequences of these will depend on prevailing circumstances in a region or production system (de La Rocque et al., 2008). In certain areas, such as the temperate and cold northern latitudes, the consequences of CC may, to some extent, be positive. A prolonged grazing season for animals can lower the incidence of infectious respiratory and gastrointestinal diseases which are associated with the indoor period. On the other hand, the exposure to VBD and para-

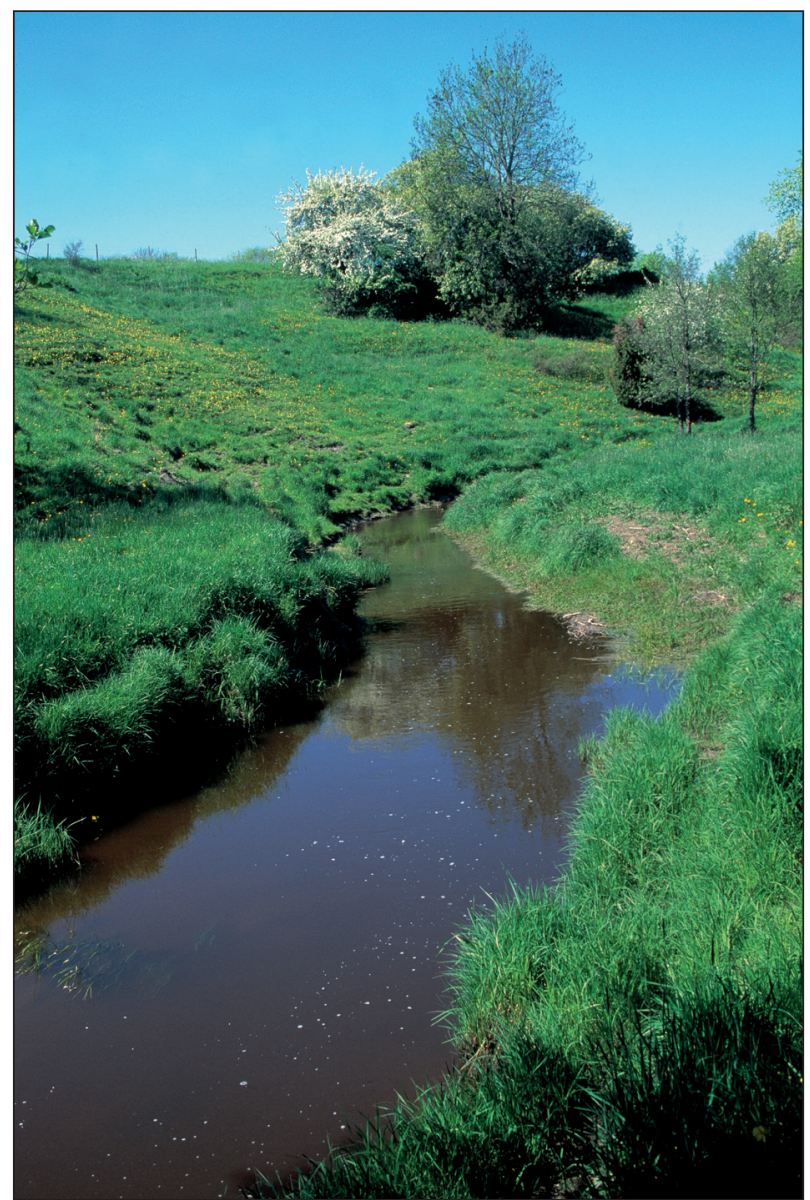

Figure 38.1. Clean water in sufficient amount will be one of the challenges with climate change. Jumkilsån. Photo: Bengt Ekberg, SVA. 
sites will be prolonged with extended outdoor periods. In addition, some parasitic diseases are suggested to become an increasing problem for animal production (Van Dijk et al., 2008; Mas-Coma et al., 2008). As the winters get warmer the ground may not freeze (IPCC, 2007) and may become wet and muddy. This can cause hygiene and health problems and infections in the skin and hooves of cattle and sheep. In addition, outdoor animals are more exposed to extreme weather events such as storms, fires, drought and flooding. In addition to the problems with VBD, dense populations of certain insects can become a serious nuisance for grazing animals.

In areas already classified as marginal today according to the possibilities for livelihood and food production, even a small change concerning temperature or precipitation events may be disastrous (FAO, 2008). Water supply concerning both quality and quantity may become a problem. Animal husbandry consumes large quantities of water for crop production, cleaning, drinking, etc. A high-yielding dairy cow consumes more than 100 litres of water per day, and thus a decrease in water quality may negatively affect animal health. A shortage of water may be one of the most severe and widespread health effects of CC. Today's dry areas are in general predicted to get dryer as $\mathrm{CC}$ progresses and the patterns of precipitation to become more irregular. An increased drought frequency can have catastrophic effects for agriculture. In production systems based on extensive grazing and relying on natural water sources, the distance for the animals to reach drinking water may become too long when water sources dry out. Heavy rainfall and flooding, on the other hand, may facilitate rapid transportation of diseases-causing pathogens into water supplies, which can potentially harm populations of both wild and domestic animals and humans. When animals drink water of low hygienic quality, they may acquire infections such as VTEC, salmonella and water-borne parasites.

A warmer and more humid climate may also create new demands for housing animals, especially under the intensive indoor production conditions used for pigs, chickens and eggs. Pigs and chickens cannot sweat and are therefore especially sensitive to heat if not provided with possibilities to seek shade or wallow in mud or water. The high-yielding dairy cow is also sensitive to heat stress (Sartori et al., 2002). In temperate and cold

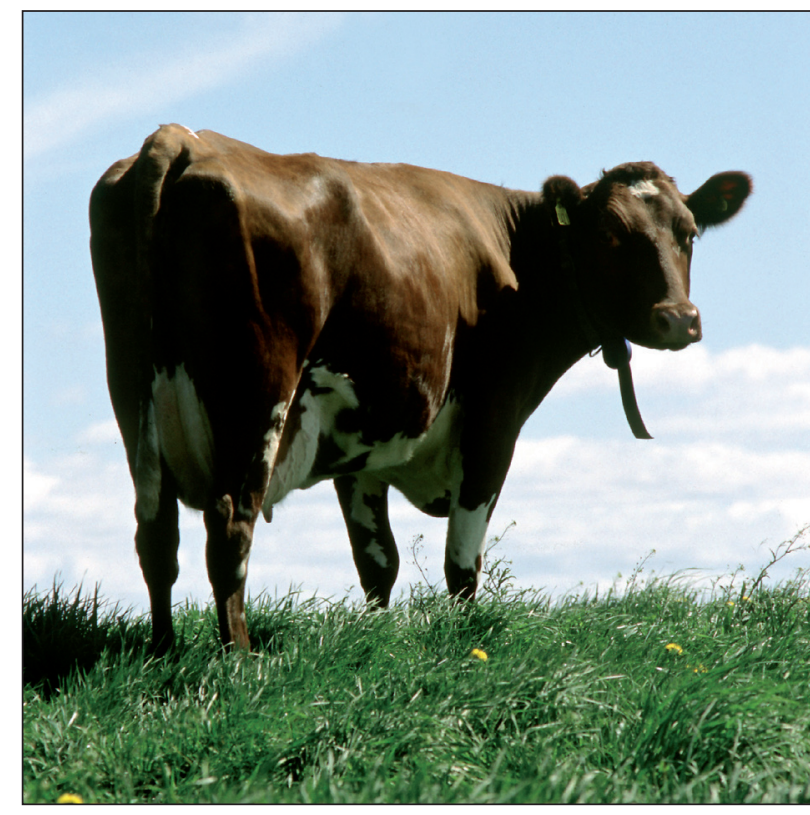

Figure 38.2. Climate change can lead to a prolonged grazing period, which both can enhance and decrease the infection risk for the grazing animals. Photo: Uffe Andersson, LRF.

northern latitudes today, farm buildings are to a large extent constructed to protect against cold weather and may not be adjusted to protect against heat. As a consequence of global warming, the construction of suitable buildings and the provision of shade from direct sunlight on pastures may become necessary in new regions when attempting to maintain high production.

In the temperate and cold northern latitudes a prolonged vegetation period may be beneficial in many ways. As a consequence of a prolonged grazing period, the need for winter feed decreases. The possibility to grow new feed crops may also arise, e.g. maize has already been introduced and established as a common feed crop in southern parts of Scandinavia. It may be possible to increase the crop yield and take an additional harvest per season. However, there may be a more insecure supply of feed. Droughts or heavy rainfall may be detrimental for the crop in some years or in some regions. There may also be a shortage of feed for grazing animals during the more frequent periods of drought and therefore a need for extra feed supply. A warmer and more humid climate makes storing feedstuffs more risky, as microbial growth may 
be enhanced and hygienic quality lowered. The presence of salmonella bacteria or mycotoxins in feed can be more common. Mycotoxin production may also occur even in the field and new species e.g. Fusarium spp. may emerge in new areas.

\section{Impact on Health - Infectious Diseases}

For both domestic animals and wildlife, new infectious diseases are a serious threat. Introduction of new infective agents may entail disastrous effects for a large proportion of individuals in an immunologically naive population and, in extreme cases, lead to extinction of entire populations. Globalisation with increased movement of animals, people and goods facilitates dispersal of disease agents far from their endemic regions (Moore et al., 1988; Harrington et al., 2005; Mintiens et al., 2008). As infectious diseases today are spreading geographically much faster than at any previous time, an epidemic or epizootic disease outbreak in any part of the world is not far away from becoming a threat somewhere else. Consequently, new diseases can arrive from 'anywhere', while CC may facilitate establishment of novel imported infectious diseases in regions that were previously unable to support endemic transmissions (Dufour et al., 2008). The mechanisms by which CC affects disease transmission have often been oversimplified, as many other factors also influence the environment and the behaviour of populations and individuals (McMichael et al., 2006; Randolph, 2008). For example, human activities such as change of land use and fragmentation of habitats can enhance the dispersal of disease agents. Extreme weather events such as flooding, storms, droughts, etc. are associated with an increased disease risk. Such events may influence infectious diseases more profoundly and acutely than the ongoing CC (Kinde et al., 1996; Kriz, 1998; Hubalek et al., 2004).

In terms of CC, VBD are a special concern (Gubler, 1998; Dufour et al., 2008; de La Rocque et al., 2008). The transmission of VBD is closely linked to nature and ecosystem structure and therefore to a large extent dependent on processes in a specific ecosystem (Hales et al., 2006). Most VBD that are expected to emerge because of CC are zoonotic diseases. Compared with 'human-only' dis- eases, zoonoses are in general more difficult to control with vaccination, education of populations and medical checks of travellers, etc. In an attempt to identify animal infectious diseases of importance whose introduction or distribution in France could be affected by CC, five out of six prioritised diseases were VBD and five of these six were also zoonoses (Dufour et al., 2008).

Although the introduction of exotic diseases to new regions is a concern, geographical and seasonal patterns of endemic infectious diseases may also be altered due to CC. It is possible that well-known, persistent diseases will change character in respect of severity, epidemiology, incidence, etc. The seasonality of outbreaks of a certain disease has long been commonly recognised. The same has been observed for periodic epidemics and disease outbreaks of less frequent or more irregular intervals. Knowledge of the mechanisms triggering epidemics with interannual cycles is in most cases sparse. Most epidemiological data concerning infectious diseases are restricted to certain periods of time or to specific countries or regions. The identification and relative importance of climatic factors for disease dynamics on a longer timescale is therefore still a controversial topic (McMichael et al., 2006). Other non-climatic aspects such as environmental disturbances and pollution, land use changes, habitat fragmentation, effects of altered behaviour, etc. also affect the incidence of diseases. These factors may have either cumulative or opposing effects on disease occurrence. For example, effects of $\mathrm{CC}$ in promoting the dispersal of 'human-only' VBD such as malaria and dengue fever from more tropical ranges to temperate areas have been observed (Epstein, 1995; Patz et al., 1996). Another interesting example of climate effects on the incidence of human infections is the El Niño Seasonal Oscillation effect (ENSO). This semi-regular climate cycle, although not perfect, can be used as an analogue for the effects of global CC (Cazalles and Hales, 2006). The ENSO event has been associated with an increase in diarrhoea in Peru, cholera epidemics in Peru and Bangladesh and dengue fever and malaria epidemics in several tropical and subtropical countries (Cazalles and Hales, 2006). ENSOevents are predicted to become a more frequent and severe phenomenon as global warming progresses (IPCC, 2007), which would further facilitate local epidemics of certain diseases. 
Another aspect of $\mathrm{CC}$ is that an effect on the pathogen microorganism itself may be seen. This has been speculated to cause an increase in the virulence of pathogens in some cases (Marcogliese, 2008). To fit a dynamic environment such as that induced by $\mathrm{CC}$, a generalist strategy is favourable. A generalist organism displays pioneer behaviour and is ready to encroach or occupy any novel ecological vacuum that may present itself. For example, the ability to infect multiple host species makes it possible for a pathogen to overcome temporary shortfalls in host availability. A pathogen with a flexible host-occupancy pattern is also an effective transmitter of infection to new species. Vector-borne viruses are often RNA viruses, which are known for their variability and limited specificity of hosts (de La Rocque et al., 2008).

\section{Opportunistic Pathogens}

Commensals or opportunistic microorganisms cause no harm when present in healthy animals. Stress caused by e.g. increased temperature, increased population density, high density of biting insects or lack of food may induce suppression of the immune response and lead to increased susceptibility of organisms to opportunistic pathogens. An example of this is an outbreak of fatal pneumonia caused by an opportunistic bacterium (Pasteurellaceae or Mannheimia spp.), which occurred in a musk ox population of Dovrefjell in Norway. A large proportion of the animals died during a period of extraordinarily warm and humid weather during early autumn 2006 (Ytrehus et al., 2008). Musk ox, like other Arctic species are adapted to extreme cold and therefore regarded as vulnerable to the impacts of CC (ACIA, 2005). Dovrefjell is a rather southerly habitat for this cold-adapted species and during early autumn the animals have a well-developed winter coat and a thick layer of subcutaneous fat, which makes them especially vulnerable to heat stress (Ytrehus et al., 2008).

\section{Parasitic Infections}

For domestic animals a prolonged grazing period has several advantages, but a negative health effect may follow from prolonged exposure to parasite infections. Warmer and more humid climates, especially in temperate and colder northern latitudes and in areas of high altitude, may shorten generation time and increase the survival and population density of parasites (Feachem et al., 1983;
Mas-Coma et al., 2008; van Dijk et al., 2008). On the other hand, e.g. a sparse protective layer of snow during the winter or less protective vegetation during drought may reduce the survival of free-living stages of the parasite or of intermediate hosts. Intermediate hosts are common in the development cycle of many parasitic organisms and play an important role in disease transmission dynamics (Feachem et al., 1983). Therefore an expansion of suitable habitats, e.g. damp areas, for invertebrate hosts may favour the existence of parasitic organisms.

Zoonotic parasites such as Cryptosporidia, Giardia and Toxoplasma can be water-borne and are suggested to cause increasing problems in the developed world, in part due to CC (Gajadhar and Allen, 2004; Mas-Coma et al., 2008). The ability of these parasites to survive for long periods of time in the environment and resist many natural and artificial conditions makes them most difficult to control (Feachem et al., 1983).

In a British study, 430000 samples of faeces from sheep with gastroenteritis symptoms were analysed for the presence of parasites during the period 1975-2006 (van Dijk et al., 2008). A highly significant increase in the rate of parasitic gastroenteritis was observed during this period and $\mathrm{CC}$ was suggested to be the most likely explanation for this increase. Possible sources of bias such as reporting bias, changes in husbandry patterns and antihelminthic resistance were also evaluated (van Dijk et al., 2008).

Under optimal conditions for an individual, many parasitic infections may not provoke any negative effect on the physiology of the host. However, under certain environmental conditions involving stress, the effects may become negative. Intestinal parasites may cause protein losses in the intestine, resulting in decreased digestive ability and increased nitrogen in the manure. Parasitic diseases, especially helminthiases, have a great impact on animal health. Under certain conditions they can also influence wild animal populations and in that way affect whole ecosystems (Mas-Coma et al., 2008). CC may cause amplification of the parasite population and have profound effects on the host-parasite assemblages. This in turn can have large impact on the health and survival of wild animal populations. Kutz et al. (2001) gives an example of this effect on a Canadian musk ox population. This population was decimated to about half during a six- 
year period due to an unusual genus of a protostrongylid lung nematode. Even though this parasite did not kill the animals, it lowered their lung capacity and made them more vulnerable to predators.

\section{Impact on Health - Heat Stress}

During the process of domestication many animals have become adapted to our temperate climate, with temperatures seldom above $25^{\circ} \mathrm{C}$. As global warming progresses, periods with temperatures above $30^{\circ} \mathrm{C}$ are expected to become more frequent. Dairy cows in particular are expected to be affected by these increased temperatures since they are to a large extent out on pasture in the summer, in many cases without shade. Moreover, the high-yielding dairy cow is more sensitive to heat stress than other farm animals due to her high feed intake and metabolic rate as a result of a progressively increased milk yield (Sartori et al., 2002).

One of the highest physiological priorities for warmblooded animals is the maintenance of body temperature. The ideal ambient temperature for dairy cows is between 5 and $25^{\circ} \mathrm{C}$, which makes it possible for the cow to maintain a body temperature of approx. $38.5^{\circ} \mathrm{C}$. At temperatures above $25^{\circ} \mathrm{C}$ cows have to use energy to cool themselves through heat loss via surface skin and the respiratory tract. As ambient temperature increases, it becomes more difficult for cows to adequately cool themselves. Temperaturehumidity index (THI) is most commonly used to measure the combined effect of air temperature and moisture in the air (Thom, 1959). It is generally accepted that when THI exceeds 74 , heat stress effects on reproduction begin to be manifested (USDC-ESSA, 1970).

Domestic pigs are also sensitive to high surrounding temperatures as they are not able to sweat and therefore cannot utilise evaporative cooling of their skin. On the other hand, the lack of substantial hair coat in pigs facilitates some heat loss from the skin surface. Under hot conditions, pigs usually attempt to increase heat transmission by increasing contact between their body and a cooler surface (floor) or wallowing in mud or water. The first physiological indicator that pigs are reacting to high ambient temperatures is an increase in respiration rate, which occurs at temperatures above approximately

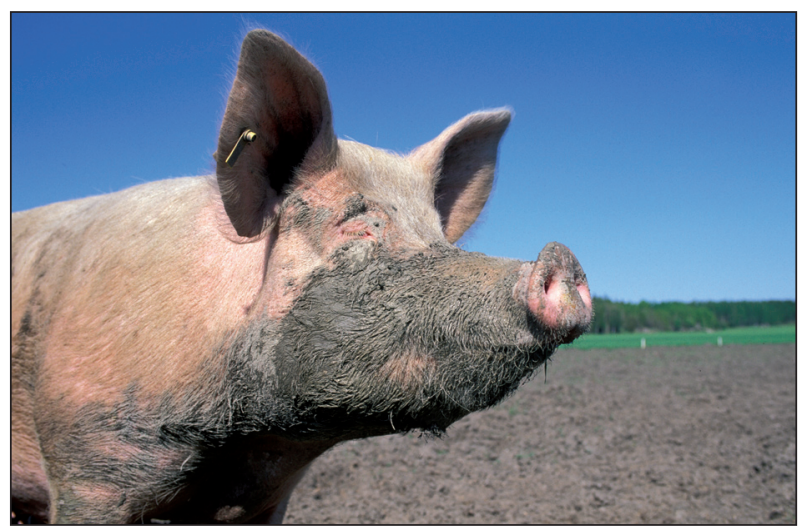

Figure 38.3.A pig covered in mud, an important way for the non-sweating pig to cool down through evaporation. Photo: Bengt Ekberg, SVA.

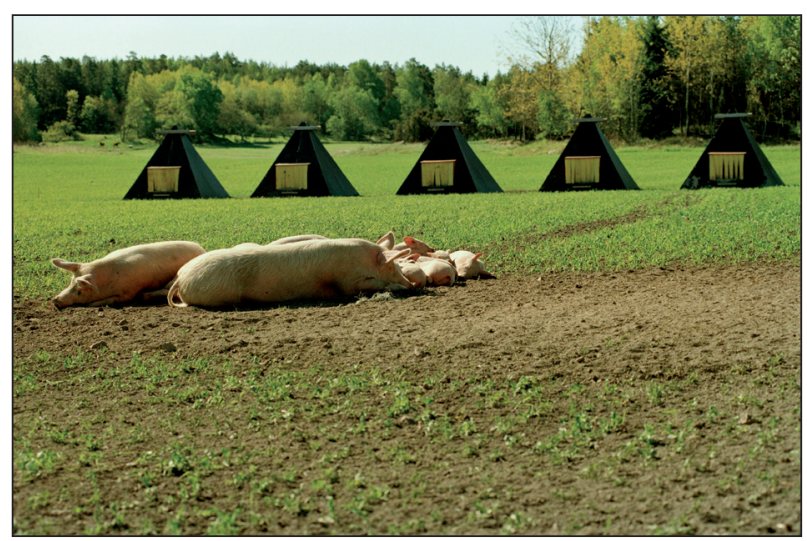

Figure 38.4. Pig huts may protect pigs from trying weather conditions. Photo: Bengt Ekberg, SVA.

$+22^{\circ} \mathrm{C}$ for pigs of around $60 \mathrm{~kg}$ (Huynh et al., 2005). Extremely warm conditions can result in the death of pigs if the possibility for supplemental cooling is not provided. However, reduced growth resulting from decreased feed intake and decreased reproduction are more common effects of increased temperatures (Quiniou et al., 2000; Suriyasomboon et al., 2006).

\section{Heat Stress and Reduced Reproductive Performance}

Heat stress has long been recognised as reducing reproductive efficiency in domestic animals in tropical areas. In particular, the impacts of heat stress on reproduction in dairy cows have been well documented (Jordan, 2003). The question is whether and to what extent the expected $\mathrm{CC}$ in 
temperate climate zones such as Northern Europe will affect the reproductive efficiency of our farm animals.

There are marked depressions in pregnancy rates per insemination during the warm months. For example, an investigation in Florida showed that the pregnancy rate in cows in July was around 10\%, compared with $35 \%$ in February (Cavestany et al., 1985). In a recent study of insemination outcomes of 16,878 services performed during 21 months in Australia, pregnancy rates were related to when THI exceeded 72 during the first 24 hours post-service. Conception rates were reduced when lactating cows were exposed to an elevated heat load ( $>24$ $\mathrm{h}$ with THI > 72) from the day of service until six days after. Weeks preceding service with an elevated heat load were also associated with reduced pregnancy outcome (Morton et al., 2007).

\section{Declining Oestrous Symptoms}

Heat stress has been shown to reduce reproductive efficiency in e.g. dairy cattle and domestic pigs by reducing oestrous expression and the duration of oestrous behaviour. A reduction in oestrous detection leads to a declining ability to perform insemination. Reduced oestrous behaviour is in part related to reduced general activity in heat-stressed cows. Cows become sluggish in a hot climate and are not willing to move or show mating attempts (Pennington et al., 1985). It has also been reported that high temperatures cause reduced peripheral concentrations of oestradiol 17- $\beta$ and a decreased gonadotrophin response to injection of gonadotrophin-releasing hormones $(\mathrm{GnRH})$, pointing at possible endocrine effects of heat stress on oestrous expression (Gilad et al., 1993).

\section{Effects on Fertilisation and During Gestation}

Early studies showed that uterine temperature and average ambient temperature on the day of insemination were inversely related to pregnancy rates in dairy cows (Gwasdauskas et al., 1973). Several recent studies indicate that disruption of the reproductive process can occur quite early - during oocyte growth or maturation, since oocytes are temperature-sensitive. According to Al-Katanani et al. (2002), oocytes collected from cows during the warm season were less likely to give rise to an embryo capable of development to the blastocyst stage than embryos collected during the cold season. Similar results were reported from Israel, where oocyte quality gradually improved as the season progressed from early to late autumn. However some studies have also shown a delayed effect of heat stress on oocyte quality, leading to a prolongation in decreased fertility even when the cows are no longer under heat stress (Roth et al., 2001). Furthermore, heat stress has been shown to change follicular dynamics in the ovary. The duration of dominance in the ovary of the preovulatory follicle has been shown to increase in hot weather and is negatively correlated to fertility (Wolfenson et al., 1995).

Embryos seem to become more resistant to heat stress as pregnancy proceeds. However heat stress has been reported to reduce uterine blood flow, which could potentially reduce the delivery of nutrients and hormones to the uterus and placenta. In a study by Collier et al (1982), the secretion of the placental hormone oestrone sulphate, placental size and calf birth weight were shown to be reduced in heat-stressed cows. In a another more recent study in north-east Spain by Garcia-Isperto et al. (2006), which involved 1391 pregnancies in Holstein cows with a mean annual production of $10890 \mathrm{~kg}$ per cow, a clear relationship was found between maximum THI on days 21-30 of gestation and subsequent foetal loss.

Early research in pigs showed that heat stress had a negative effect on embryo survival during the first 30 days of pregnancy, whereas during mid-pregnancy it did not influence the number of pigs born per sow. However, when pregnant gilts were stressed during the last two weeks of pregnancy, an increase in the number of stillborn pigs per sow was observed. Further research has shown that the first five days of pregnancy are especially critical for sows to become heat-stressed (Suriyasomboon et al., 2006). Heat stress during lactation causes reduced feed intake, leading to reduced milk production and weight loss. Pig producers, especially in tropical areas, utilise several methods to minimise heat stress e.g. water sprinkling, ventilation, increased floor space and shaded areas.

\section{Effects on Male Fertility}

In male mammals high temperatures impair spermatogenesis. The effects of heat on sperm production include decreased sperm numbers, decreased sperm motility and increased numbers of abnormal sperm. Primary (immature) spermatocytes are especially susceptible to 
elevated temperature. Consequently, males of many species have evolved anatomical structures for local thermoregulation that involves placement of the testes at the periphery of the body. As a result, testicular temperature is approx. $2-4^{\circ} \mathrm{C}$ below body temperature. A negative effect of temperature on male fertility has been known for centuries. Furthermore cryptorchids, animals whose testes do not descend into the scrotum, are infertile. However in some animals e.g. elephants and dolphins, the testes remain inside the abdomen. Cooling of testes in these species is often achieved by alternative physiological solutions: for example in dolphins the testes appear to be cooled by venous blood from the tail running into the abdominal cavity next to the arterial supply for the testes. Spermatogenesis in many animals is disrupted when either the thermoregulatory system of the testes is defective or when body temperature becomes elevated in general because of fever or heat stress (Cameron and Blackshaw, 1980). A well-known case is the summer sterility affecting rams in Central Australia, which may also occur in natural populations of wild animals. There is a delay of about two weeks between heat stress and the first alterations visible in the semen. It is also notable that the effects of heat stress on sperm output in the bull persist for 7-8 weeks after the end of heat stress. Some recent studies suggest that the effects of heat on the testes are never fully reversible. However, there is a considerable variation between individuals and breeds and their response to heat exposure. For example, Bos indicus bulls are less sensitive to the effects of high temperature than Bos taurus bulls (Setchell, 2006).

\section{Impact on Ecosystem Health}

Changes in ecosystems as a consequence of $\mathrm{CC}$ will have a profound impact on ecosystem health. Today an obvious effect of $\mathrm{CC}$ has been observed on the distribution of vertebrates, invertebrates and plant species, on timing of seasonal activities of species and on physiological responses in both terrestrial and aquatic organisms (Marcogliese, 2008). Ecosystems with a low biodiversity, e.g. in Arctic and sub-Arctic climate zones, are more sensitive to changes (ACIA, 2005) that the more diverse systems (Parmesan, 2006). Continuous and systematic assessment of wildlife health can provide a means to estimate ecosystem health, e.g. infectious diseases are one manifestation of deteriorating ecosystems. New diseases may cause epizootics, especially if the native biota is immunologically naive to the new agent.

Predicting how ecosystems are likely to respond to further CC is complicated. Multiple factors and changes may be of importance for ecosystem health and in some cases other factors may play an even greater role than CC. Human modifications of landscapes such as deforestation, urbanisation, agriculture, coastal zone management and also consequences of pollution are already threatening many different kinds of environments. Complex ecological interactions result from several factors working in unison or in tandem. Sudden, fundamental changes (threshold changes) in ecosystems can already be observed today and further anthropogenic changes can magnify the health effects of $\mathrm{CC}$ and extreme weather events. Taken together, the present and coming changes in ecosystems will have profound implications for epidemiology and animal health.

\section{Species Distribution and Importance of Biodiversity}

In general, biodiversity is highest in the tropics and lowest in the Arctic and sub-Arctic climate zones. Loss of biodiversity increases the vulnerability of the ecosystem and may tip the ecological balance. For example, declines in predator populations can disrupt the natural biological control system of prey species, which can, as a consequence, become pests and carriers of pathogens (Epstein, 2002). At present, a marked change in the existence and geographical distribution of many species can be observed (Parmesan, 2006). It has been predicted that as many as $30 \%$ of animal species may disappear (www.iucnredlist. org) because of recent changes. In retrospect, during past periods of $\mathrm{CC}$ the survival of species has been relying on different strategies. A shift in distribution by migration to areas of more suitable climate has been a common historical way of survival. Temporary establishment in refugee areas has often been practised, together with downsizing in population numbers and in distribution area. However, a higher density of an animal population, as may follow migration, can create an opportunity for density-dependent pathogens to cause disease outbreaks. Today, many 
examples of species shifting upward in altitude and northward in latitude can be found (Lovejoy, 2008). Species in the Arctic/Antarctic and high latitude locations will be particularly vulnerable, as there will be no possibility for a climatic shift in terms of altitude or latitude (ACIA, 2005). In addition, the expected average temperature increase will be highest close to the poles (IPCC, 2007). Another survival strategy during periods of $\mathrm{CC}$ is adaptation by genetic selection, but examples of this strategy are rare and often debated (Parmesan, 2006).

In general, VBD today are more prevalent in the tropics, since the warm and humid climate there provides ideal conditions for vectors. However, the large diversity and abundance of different infections in the tropics is most likely buffered by the large biodiversity, causing a 'dilution effect'. Through this, the presence of incompetent disease reservoirs decreases the impact of highly competent reservoirs and reduces the disease risk (Marcogliese, 2008). Vectors can only bite a limited number of times during their lifetime. If some bites are spent on individuals that are non-competent to either amplify or transmit the pathogen, those bites are wasted. If VBD disperse to higher latitudes and altitudes under warmer climate conditions, they will invade ecosystems in which the natural level of biodiversity is relatively low. If the most competent vector or reservoir host becomes dominant, the risk for a high prevalence of the infection will increase (Schmidt and Ostfeld, 2001; Marcogliese, 2008). Furthermore, some host species may also spread from the tropics into the temperate zones. However, larger species typically spread at a slower rate than smaller, so for a significant time VBD will be moving down a gradient of biodiversity (Dobson et al., 2006). Therefore it may be wise to conserve biological diversity for the purely selfish reasons of protecting human and domestic animal health.

\section{Impact on Health of Wildlife}

From one point of view wildlife may act as a disease reservoir, transmitting infections to domestic animals or humans. On the other hand, as mentioned above, wildlife and the ecological communities play a major role in regulating the natural abundance of zoonotic and animal pathogens that may infect humans and their domestic livestock (Dobson et al., 2006). When wildlife acquires a pathogen, the actual species may act as a reservoir for

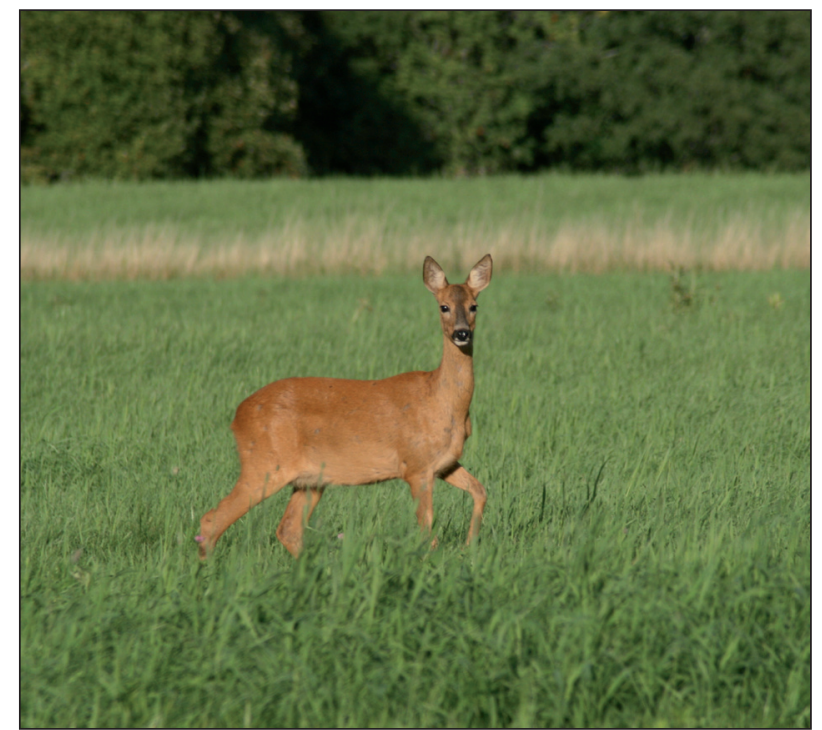

Figure 38.5. Wildlife can act as a reservoir for infectious diseases. Photo: Roland Mattsson, SVA.

a certain disease for a prolonged time without displaying clinical symptoms. Since CC may alter the presence of wildlife species, the presence of several diseases may also be altered. Usutu virus (USUV) is an example of an infection causing mass mortalities of birds and it was diagnosed in Austria in 2001, which was the first time outside Africa (Brugger and Rubel, 2009). Blackbirds (Turdus merula) and great grey owls (Strix nebulosa) around Vienna were particularly affected. The virus was most probably transferred from Africa by migratory birds. The transmission cycle between birds and the mosquito vector (Culex pipiens spp.) depends strongly on the environmental temperature. USUV is a rather unknown virus since it is mainly a problem in wild birds, although it has shown zoonotic potential (Brugger and Rubel, 2009).

It has been noticed that hunting and fishing have been much harmed by recent $\mathrm{CC}$ in some regions, through stresses on animals driven by ecosystem shifts as sea ice retreat or warming of air and sea (ACIA, 2005). In food-insecure human populations, this alteration may already be contributing to malnutrition. There is an inability of many species to adapt to the relatively rapid ongoing changes in the ecosystems, resulting in a marked decline in population number or even to species extinc- 
tion (Lovejoy, 2008). The decline or extinction of a key species can have severe effects on the whole ecosystem.

Habitat fragmentation, introduction of new species, scarcity of feed and water, deforestation and many other anthropogenic activities will stress wildlife populations. The impact of $\mathrm{CC}$ will be superimposed onto the effects of other stressors in ecosystems. This combination may work cumulatively or synergistically to exacerbate negative effects on populations or ecosystems (Marcogliese, 2008; Ytrehus et al., 2008).

$\mathrm{CC}$ affects both water availability and quality. Shortage of water may cause wildlife density to increase in the neighbourhood of a water source and this in turn could enhance the spread of infectious diseases, both within and between species. In the same way, forced migration could enhance transmission of disease due to intermingling of populations with introduction of novel diseases into non-immune populations.

\section{Ecosystem Interactions and Dynamics}

An ecosystem is a naturally occurring collection of organisms, plants and animals co-existing in a certain area and mainly dependent on the same environment. Different ecosystems are more or less sensitive to disturbances depending on environmental factors and inhabiting species. In general, more sensitive ecosystems are found in the Arctic and sub-Arctic climate zones than in temperate or tropical zones, largely due to lower biodiversity in the former.

Climate change directly affects ecosystems by changes in snow and ice cover, precipitation and temperature, etc. A secondary effect may be seen on biodiversity, population dynamics, home range size, migration patterns, habitat use, etc. The occurrence of new species may have effects on introduction of new infectious diseases, predation, vegetation and also on their competitive relationships. The possibilities for adaptation to a changed environment vary from one species to another. Effects may also arise from dense populations of insects, ticks, etc. considerably disturbing mammals and birds and also acting as vectors. For example, rodent breeding increases during mild weather and decreases in times of drought or heat. However, drought may also drive rodents to seek in- door sources of water, increasing the risk of disease transmission if humans and domestic animals come in contact with rodents or their secretions or excrement. Rodents play an important role as a reservoir host for many tickborne diseases (Hartelt et al., 2008).

Changes in the vegetation may result from changed temperature and precipitation and thus indirectly affect the animal community at all ecosystem levels. A changed vegetation cover will affect the quantity, quality and accessibility of feed plants. Warm winter events in the Arctic and sub-Arctic zone will affect winter grazing conditions by the creation of ice cover on the ground (ACIA, 2005). Animals can exert further feedback on the vegetation and fundamental ecosystem processes such as soil nutrient recycling.

Species may be forced to migrate due to extreme weather events, changing ecosystems due to ongoing CC or other reasons causing unfavourable changes in habitat. Invasive exotic species may compete for feed and space but can also bring disease agents into a vulnerable host population, causing severe outbreaks of disease. Human penetration into remote areas may bring new pathogens to the ecosystem, but may also bring humans or domestic animals into contact with previously 'isolated' pathogens.

\section{Marine Ecosystem}

While temperature and moisture are the most important environmental parameters for land-living animals, temperature and $\mathrm{pH}$ are the two most important for aquatic species (Lovejoy, 2008). Ocean temperature increases while absorbing most of the heat added to the climate system. Aquatic life is often strictly adapted to a certain temperature range and will therefore be exposed to a significant level of stress at temperatures outside this range.

The uptake of carbon dioxide will make sea water more acidic. This profound change in oceanic chemistry has worrisome implications for species constructing their shell and skeleton out of calcium carbonate, including those that exist in untold numbers at the base of marine food chains (Lovejoy, 2008). In marine environments, plankton species as well as fish species have been shifting geographically (ACIA, 2005; Lovejoy, 2008).

Changed salt levels are another part of the problem. Depending on the different IPCC emissions scenarios based on different data and assumptions, the Baltic Sea is 
predicted to warm up as much as $4^{\circ} \mathrm{C}$ during the present century (IPCC, 2007). A higher temperature lowers the maturation of oxygen, which increases the stress already present in this marine ecosystem. High temperatures in surface water and greater hypoxia in bottom waters will confine fish to narrower bands of tolerable conditions, where they will seek refuge at higher densities. This in turn may serve to increase disease transmission (Marcogliese, 2008). Aquatic organisms under stress are more sensitive to infections than land-based animals and perform less well in terms of growth and reproduction (Marcogliese, 2008). Diseases may be introduced with invading exotic species or opportunistic pathogens, but diseases already present in the population may also cause disease outbreaks in aquatic species immune-suppressed due to stress.

\section{Altered Persistence of Pathogens in the Environment} Although VBD are the main focus when concerning the impact of $\mathrm{CC}$ on infectious diseases, infections transmitted through the environment, e.g. water and soil, are also of interest. Infections may be transmitted to grazing animals or by feed and water. Increased air and water temperatures may improve the survival and proliferation of some pathogens (Mitscherlich and Marth, 1983). Although pathogens occur naturally in the environment, in many cases there is a man-made cause for the environmental presence of many pathogen microorganisms. Pathogens may be introduced into ecosystems when biological waste of agricultural, municipal or industrial origin is recycled in agriculture or deposited in the environment in other ways (Albihn, 2009). Once pathogen pollution has taken place, it is often impossible to control the spread of the infective agents either in time or space.

Some vegetative bacteria may survive in the environment for over one year if temperature, humidity, type of soil, etc. are favourable (Mitscherlich and Mart, 1983). Different soil types affect microbial survival in different ways owing to their texture, pore space, surface activity, moisture-holding characteristics, presence of essential nutrients and type of autochthonous microorganisms, etc. Some pathogenic bacteria such as Salmonella and VTEC can also multiply in favourable circumstances, such as in warm and humid weather (Mitcherlich and Marth, 1983). To enhance persistence, different Salmonella serovars ad-

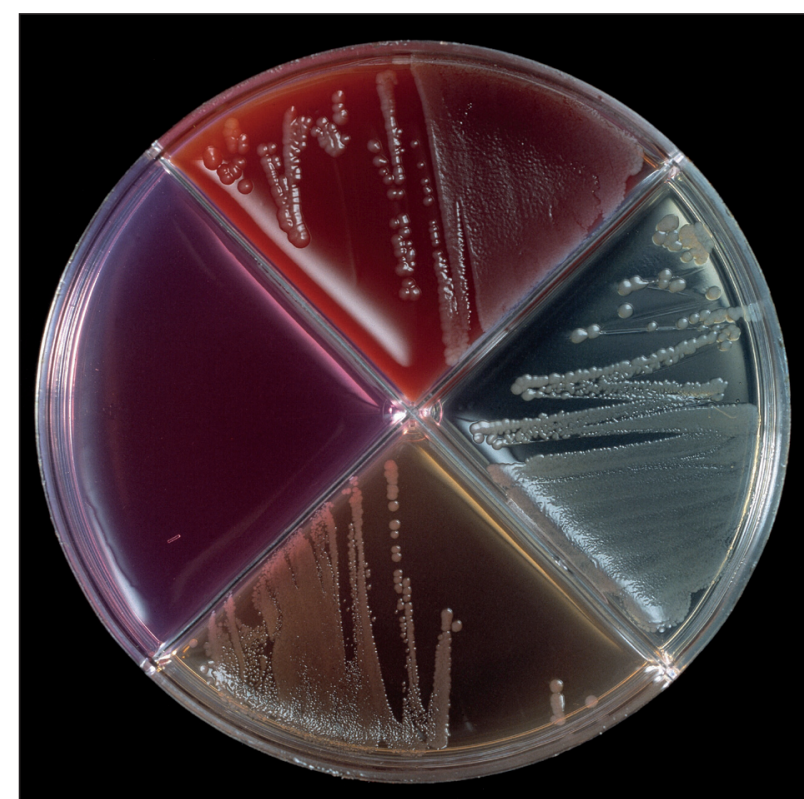

Figure 38.6. Blood agar with Salmonella Dublin growth. Salmonella is a bacterium which epidemiology can change as a response to climate change. Photo: Bengt Ekberg, SVA.

just themselves to the surrounding circumstances in different ways (Mitcherlich and Marth, 1983).

Spore-forming bacteria such as Bacillus and Clostridia species are extremely persistent in the environment and may stay viable for decades buried in dry soil, where microbial activity is minimal. There are several reported examples of unexpected infections of cattle after digging in places where anthrax-infected carcasses had been buried decades previously. In the surface layer of soil, in competition with other organisms, anthrax spores can disappear within a few years. In Germany, it was noted that the anthrax losses of cattle on pastures drastically diminished during World War I. These pastures were flooded annually by water from a river and tanneries had drained their spore-contaminated sewage into this river (Mitcherlich and Marth, 1983). Cattle losses due to anthrax increased subsequently once contaminated hides were again imported after the war. Other interesting observations concerning the potential of Bacillus anthracis to multiply in soil have been made during periods of major climatic and ecological changes in which the soil microenvironment 
is altered in such a way that spores start to germinate and multiply (Mitscherlich and Marth, 1983).

\section{Altered Presence and Epidemiology of Vector-borne Infectious Diseases}

VBD have become an increasing problem in recent years and are of special interest in relation to $\mathrm{CC}$ and ecosystem changes (Gubler, 1998; Dufour et al., 2008). These disease agents are transmitted from one vertebrate host to another in a transmission cycle that includes a biological vector, which might be an insect, such as mosquitoes or fleas; or other arthropod, such as ticks or mites. In a broad sense, birds (Hubalek, 2004) and mammals (Randolph, 2008) may act as vectors, and sometimes the disease agent is transmitted physically or mechanically (e.g. on the feet of flies) but in this chapter the emphasis is on infectious agents carried by arthropod vectors and transmitted biologically. Some VBD often mentioned in connection with $\mathrm{CC}$ are Eastern and Western equine encephalitis, West Nile fever, blue tongue and Lyme disease (Epstein, 1995; Rogers and Randolph, 2006; Takken and Knols, 2007; Dufour et al., 2008; Gould and Higgs, 2009).

Historically, both animal and human populations in Europe and North America suffered from numerous pests and VBD. Introduction of hygiene measures, drugs and vector control caused the disappearance of many of these diseases from more economically developed and climatically temperate nations (CDC, 2004). In warmer climate zones, many diseases no longer seen in Europe and North America still thrive, causing serious health problems for humans and animals. Today we are aware of the risk of introduction and spread of exotic VBD to new regions and the persistent presence of such diseases in these new regions. This has been seen e.g. for West Nile fever introduced into the USA in 1999 (Blitvich, 2008) and for blue tongue disease in Northern Europe from 2006 (Gould and Higgs, 2009).

Most species, including humans, may act as a host for some VBD agent. However, only a few VBD (e.g. dengue fever and malaria) are strictly dependent on humans as a host, whereas most pathogens have the ability to infect a variety of hosts. A host might play the role of reservoir, where the microorganism matures or increases in number so that it can be picked up through ingestion by a vector and further transmitted, or it might be a dead-end host. In this case, the host might itself carry the agent and eventually become ill, but some characteristic of the host, agent, vector or environment prevents the agent from being further transmitted through the vector. A third type of host is known as an intermediate host, whereby an agent is present in the host during an intermediate stage of development.

\section{Climate Change and Vector-borne Disease - How does it fit Together?}

The concern today is for increased incidence of VBD is due to CC. Environmental conditions are important for the presence of many vectors (ticks, mosquitoes, sandflies, etc.), as well as the mammalian or avian host species they use to feed on or which act as reservoir species for the disease agent. The transmission cycle for infectious agents carried by vectors can be complex, and it is especially important to understand this cycle for any given agent and its geographical context in order to understand how climate plays a role. In general, vectors are favoured by increased temperature and high humidity. However, increasing precipitation is not always favourable for vectors. Heavy rainfall may wash away breeding sites, while drought, on the other hand, may slow rapid streams and create pools of stagnant water.

To a large extent, other non-climatic causes of ecosystem changes, such as pollution, land use changes, population increases and fragmentation of habitats, may also play an important role in changing vector transmission cycles. A particular concern as regards $\mathrm{CC}$ is the potential for temporary introductions of diseases supported by increased populations of vectors during exceptionally warm summers. While temporary outbreaks of most exotic VBD will most probably die out during the following winter, the impact on human and animal health may be considerable.

It is the complexity involved with the life cycles of the different hosts and vectors and the microorganism that make VBD difficult to predict and control, and this complexity also results in a disease ecology that can be modified due to CC. The distribution and size of populations of vectors and hosts will respond to changes in temperature and precipitation and these can often produce an outcome of changing disease patterns (Daniel et al., 2003). 
An attempt has been made to simulate the influence of $\mathrm{CC}$ on replication and population size of ticks and the secondary effect on disease transmission of three different pathogens by using a mathematical model (Ogden et al., 2008). The seasonal synchrony of different development stages of ticks is important for the population biology and this is to a large extent temperature-dependent and therefore may be altered by CC. However, the results from the mathematical modelling were difficult to interpret, since the influence of $\mathrm{CC}$ was different between different tick species and geographical locations and even amongst different populations of the same species, as an effect of evolutionary processes (Ogden et al., 2008). In addition, the relationship between ambient weather conditions and vector ecology is complicated by the natural tendency for arthropod vectors to seek out the most suitable microclimates for their survival. Example of this are resting under vegetation or in pit latrines during dry or hot conditions or in culverts during cold conditions (Gubler et al., 2001).

Three important and contrasting examples of VBD agents for which the range has changed recently are West Nile fever virus (VNFV) in the United States, blue tongue virus (BTV) in Northern Europe and Borrelia burgdorferi, the bacterial agent of Lyme disease, in both the US and Europe. The three disease agents in question are spread to different hosts through different arthropod vectors: mosquitoes for WNFV, midges for BTV, and ticks for B. burgdorferi. Each disease system responds differently to ecosystem changes and changes in temperature, humidity, etc. Below we consider the disease transmission for each agent to illustrate the varied dynamics of VBD and CC.

\section{West Nile Fever Virus}

West Nile fever virus (VNFV) is a flavivirus and was identified in 1937 in the West Nile region of Uganda. After a period of mostly sporadic outbreaks reported in humans, geese and horses in Africa, southern Europe and the Middle East, it made a surprise jump across the Atlantic Ocean, to New York City, in 1999 (Hayes, 2001). From there it spread rapidly across North America, with more than 27,000 human cases and 25,000 equine cases of illness in the period 1999-2007 (Blitvich, 2008; Reiter, 2008). The transmission cycle of the virus involves avian reservoir hosts and a mosquito vector, most often from the genus Culex (Ebel et al., 2005; Reisen et al. 2005; Hamer et al., 2008).

Seasonality is a key component of climate. Many VBD are seasonal, and in the northern latitudes they are most often seen in the warmer months, tied to the life cycle of the vector. West Nile fever in North America peaks in midAugust, and nearly all cases reported occur between July and October (CDC, 2008). Now consider the interaction between climate and WNFV in the United States Great Lakes region. The Culex mosquito that transmits WNFV in this region is affected in several ways by increased temperatures. A female Culex mosquito deposits eggs about 5-6 times during her life. With a longer period in

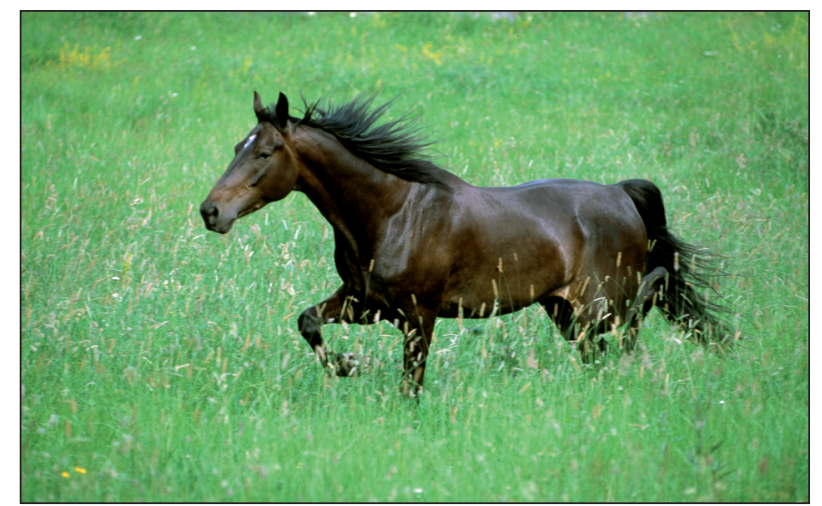

Figure 38.7. Grazing horses can be infected with Wets Nile fever virus from bites of Culex vectors. Photo: Bengt Ekberg, SVA.

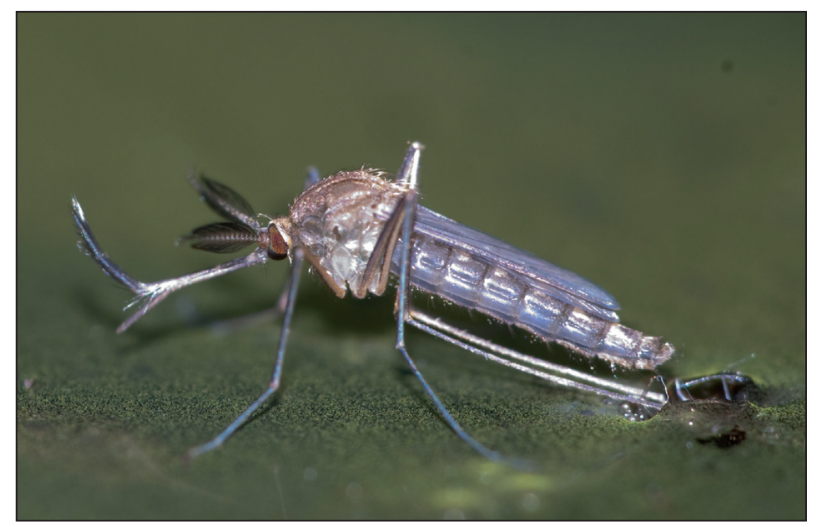

Figure 38.8. A mosquito from the genus Culex, which is one of the vectors that can spread West Nile fever virus. Photo: Anders Lindström, SVA. 
which warm temperatures prevail, more opportunities for depositing eggs are available (Reiter, 2008). Mosquitoes develop from larvae to pupae to adult. They develop faster when temperatures are warmer. When temperatures reach about $17^{\circ} \mathrm{C}$ and daylight is reduced, mosquitoes either die off or enter their winter state of inactivity, called diapause (Dohm et al., 2002). Currently in this region, there are about 18 weeks a year in which temperatures are, on average, above $17^{\circ} \mathrm{C}$. An increase in overall temperature would extend this time period, allowing more vectors to be produced. During the spring, the active season for mosquitoes could start earlier too, since water temperatures greater than $15^{\circ} \mathrm{C}$ allow their proliferation.

In addition to the potential for more vector mosquitoes to be present, those mosquitoes may transmit the virus more efficiently at warmer temperatures due to a shorter extrinsic incubation period (the time it takes from when a mosquito receives the virus until it is able to transmit the virus to its next host). For example, at $18^{\circ} \mathrm{C}$, this period can be more than three weeks, while at $30^{\circ} \mathrm{C}$, the incubation period can be as short as just four days. Overall, the replication of the virus is temperature-dependent and warmer temperatures increase the replication rate (Saegerman et al., 2008).

It is interesting to note that both the epidemics and clinical symptoms in different host species are totally different in Europe and Africa compared with North America (Reiter, 2008). The reason for this may in part be the development of immunity among wildlife in Europe, but to a large extent this difference is unknown (Reiter, 2008). Climate change is clearly very important in determining whether or not WNFV is efficiently transmitted between vertebrates and mosquitoes, but $\mathrm{CC}$ has not played an obvious role in the epidemic outbreaks seen in North America. More important factors have probably been the availability of competent vector species, the wide range and large numbers of susceptible species of migratory birds and different human activities (Reiter, 2008; Gould and Higgs, 2009).

\section{Lyme Borreliosis}

Lyme borreliosis is caused by Borrelia burgdorferi, a spirochete bacterium carried by ticks largely from the genus Ixodes. It emerged in the 1980s as an important illness of dogs, humans and some other species in North America

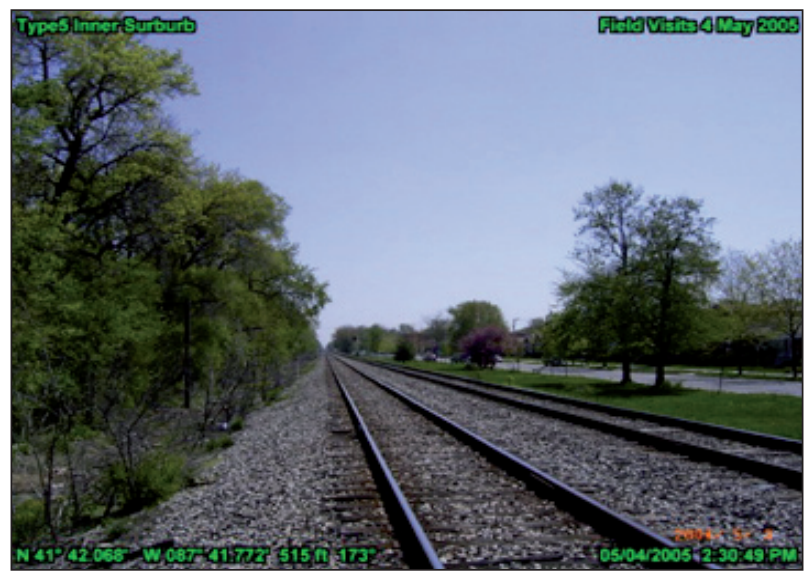

Figure 38.9. The Chicago suburbs grew quickly in the 1950s. The neighborhoods that developed have, today, proven to have ecosystem characteristics that are conducive to the transmission of West Nile virus (WNV) to avian and human hosts. Railroads cutting through the neighborhoods are one of the primary semi-natural areas, with good bird habitat for many species. Here, the photograph is tagged with information related to a research project on WNV transmission dynamics. Photo: Marilyn Ruiz.

and in Europe (Vrbova and Middleton, 2006). The Ixodes tick goes through three stages over two years as the larval tick matures to a nymph and then becomes an adult. The tick requires a blood meal to mature to each stage. The tick poses the greatest risk to humans and dogs in the spring and summer of its second year, when it is a nymph. At that point, it may have become infected as a larva and can now infect its new host (Hubalek, 2009). In the later summer and autumn, in the adult stage, it prefers a deer host but can also infect humans during that period. In North America, the reservoir host for B. burgdorferi is the white-footed mouse (Peromyscus leucopus) (LoGiudice et al., 2003).

While reduced summer precipitation leads to fewer ticks due to desiccation, increases in winter temperatures may allow for an extension of the northern boundary of the tick (Jones and Kitron, 2000; Lindgren et al., 2000). For example, the tick Ixodes ricinus was not found above $61^{\circ} \mathrm{N}$ prior to 1980 , but has now found its way to the Baltic region, at $66^{\circ} \mathrm{N}$ (Gray et al., 2009). Increased precipitation appears to play a role in tick abundance, although not in excess (McCabe and Bunnell, 2004). It is also possible that the population of white-footed mice will 


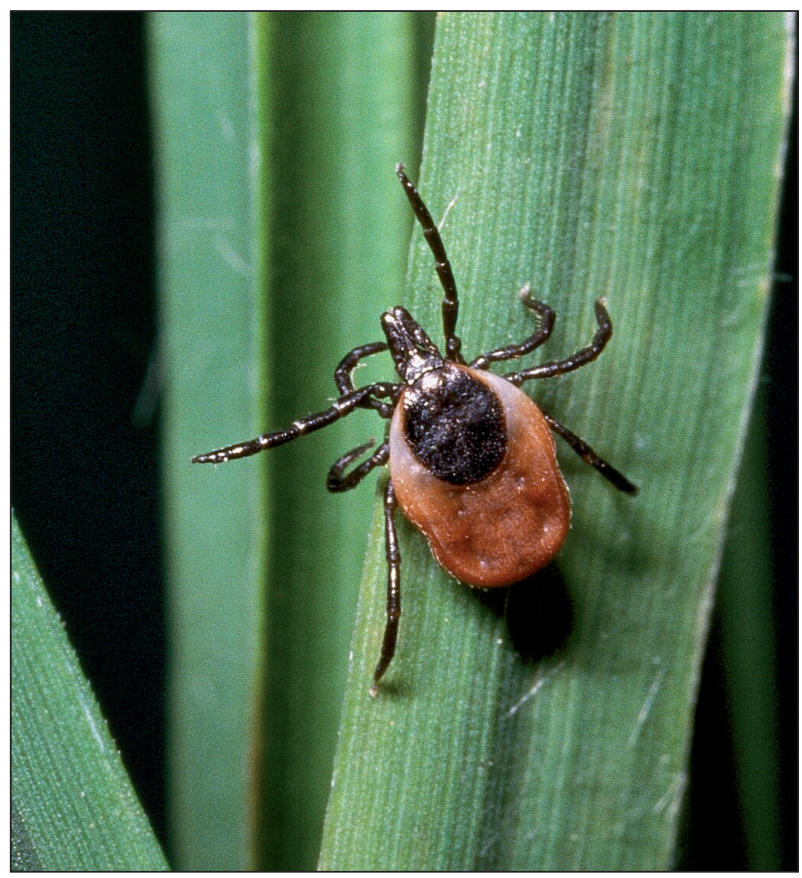

Figure 38.10. Tick on grass. A tick is a common vector for the spirochete bacteria Borrelia burgdorferi, the causing agent of Lyme borreliosis. Photo: Bengt Ekberg, SVA.

be enhanced with an increase in important food sources that can vary due to climatic factors. Ostfeld et al. (2006) noted that acorn (Quercus spp.) abundance two years prior led to higher abundance of white-footed mice and this was linked to B. burgdorfer disease. While this empirical analysis may not be directly generalised to other regions, it illustrates that an indirect path of climate that affects the acorn crop also affects the number of rodents (and deer) in an area, which in turn influences the number of ticks at various stages.

Tick-borne disease systems are very sensitive to CC through the impact of temperature and moisture stress on population size. However, it is not reasonable to expect tick abundance or seasonal activity patterns to respond to $\mathrm{CC}$ in ways that inevitably increase the risk of tick-borne infections (Dufour et al., 2008; Randolph, 2008).

\section{Blue Tongue Virus}

Blue tongue virus (BTV) recently emerged into northern Europe. Before 2006, BTV was not noticed further north than around the Mediterranean Sea (Mehlhorn et al., 2008; Purse et al., 2008; Saegerman et al., 2008). This has raised great concern as to the mechanism and implications for the rapid change in the range of the virus. The vector of BTV is Culicoides biting midges, found very commonly in and around cattle and sheep farms (Zimmer et al., 2008). BTV is an Orbivirus and can infect almost any ruminant. Wild ruminants, including red deer and roe deer, have been found to have antibodies to BTV, and the potential for these to serve as reservoirs is an important consideration in control efforts (Ruiz-Fons et al., 2008). However, the recent experience with BTV-8 in Europe suggests that 'spillover' into deer occurs only when there are high infection levels in farmed ruminants. In England, at present, wild ruminants do not appear to be an important reservoir for BTV-8 (VLA, 2007).

When illness is seen, the virus causes haemorrhagic disease, especially in sheep. BTV is a common and important disease of domestic livestock around the world, and there are 24 different serotypes and numerous strains. The remarkable increase in northern Europe of the serotype BTV-8 has caused millions of cases of illness, with disruptions of trade. Control of this disease through vaccines is still associated with several problems and vaccines need further development (Purse et al., 2008; Saegerman et al., 2008; Gould and Higgs, 2009).

Recent CC in Europe are being strongly considered as the driving factor behind the northern expansion and effectiveness of Culicoides vectors in transmitting BTV (Purse et al., 2008). These insects are small and not strong fliers, but can be carried as aerial plankton for distances up to $700 \mathrm{~km}$ (Sellers, 1992). Drivers of the expansion of BTV in Europe include several environmental conditions such as a minimum temperature during a minimum period of time. Temperature seems to play the largest role (Purse et al., 2008). In particular, the warmer winters allow more adults to survive into the spring. Then, during the warm months, the extrinsic incubation period of the virus in the vector is shorter at higher temperatures and viral replication is also enhanced. Transmission conditions are ideal when temperatures are not so warm so that survival of the adult vector is threatened (above about $30^{\circ} \mathrm{C}$ ) but when other conditions are optimised. Other effects of a higher ambient temperature are an increased biting rate and the possibility of non-vector competent Culicoides 


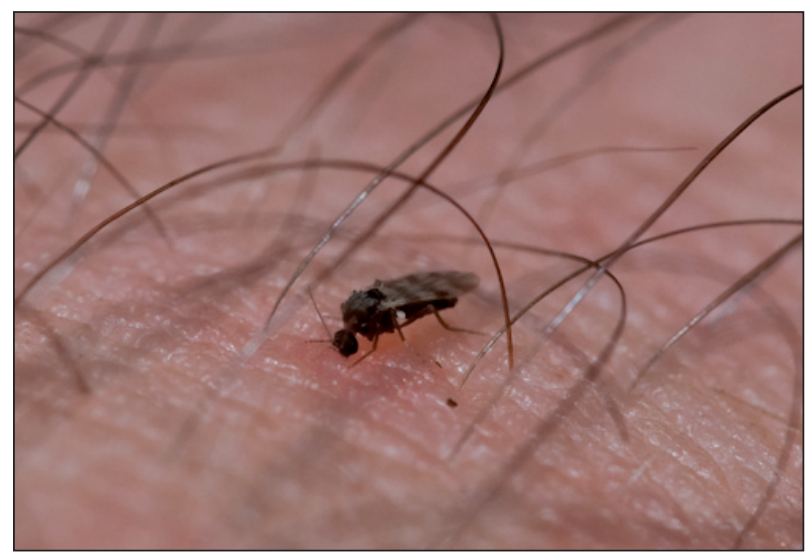

Figure 38.11. Biting midges, Culicoides, are vectors that can spread Blue tongue virus. Photo: Anders Lindström, SVA.

species and individuals becoming vector-competent and the Culicoides population increasing in density due to the higher reproduction rate (Wittmann and Baylis, 2000). The 'baton effect' is also dependent on a warmer climate. Hence, when a vector-competent species expands its distribution northwards, it may bring BTV into the range of other Culicoides species that occur much further north and are, or become, vector-competent. This species may then spread the virus over a large geographical area in a short time (Wittmann and Baylis, 2000). The vector capacity for BTV should be considered as temporally and geographically variable within and between Culicoides species, due to genetic, environmental and unknown factors (Purse et al., 2008). This may well be one of the reasons for the present northward spread of BTV in Europe.

The impact of CC is obvious on vector range expansion and the northerly establishment of BTV-8 in Europe but the transportation of infectious ruminants and the wind-borne dispersal of infected midges are believed to be highly significant contributing factors to the introduction of BTV (Purse et al., 2008; Gould and Higgs, 2009).

\section{Vector Control Efforts}

In developed countries, the systems currently used to control exotic animal infectious diseases are based mainly on monitoring animal movements and on detecting and destroying infected animals. These methods may be inadequate for VBD when a reservoir is established in vectors and/or in reservoir species among wildlife. Different control strategies for vectors may help in disease prevention and control, especially at times with high vector population density or when new vector species, e.g. the Asian tiger mosquito (Aedes albopictus), is detected in a new region.

Great vector control programmes using insecticides/ biocides in the environment are currently in place in several continents to fight major human infections such as malaria and leishmania. However, the lesson that has been learned from most of these efforts is that as soon as the treatment is finished, the insect problem becomes just as bad as before (WHO, 2004). Due to CC, the problems concerning a number of VBD may increase. This may cause the use of pesticides to be intensified, both in the environment and directly on animals and humans, in barns and houses, etc. For domestic animals insect repellents may be an option, but are not always practical or realistic. Impregnated ear tags or regular dipping of production animals in insecticide pharmaceuticals are a routine in certain areas. Such treatment, especially against ticks, may become more widespread in the future. Here organic production is facing a special problem, since this kind of treatment is not allowed.

There are several problems associated with chemical control efforts. Firstly, it is not uncommon for the target organism to adapt or develop resistance to the pesticide. Secondly, a substance may be harmful to the health of the humans who have to handle it and there may also be residues of the substance in food. In the UK the use of pyrethroids on livestock has raised environmental issues and in the US pyrethroids used to control WNFV have come under scrutiny for possible carcinogenicity in humans (Gammon, 2007). In Europe, it has been suggested that chemical vector control should be limited to application in indoor conditions (WHO, 2004), due to possible impacts on public health and the environment.

The use of biological control for the management of pest insects pre-dates the modern pesticide era. The first major successes in classical biological control occurred with exotic pests in plants controlled by natural enemy species collected from the area of origin of the pest (Bale et al., 2008). Biological control also includes the introduction of enemy microorganisms for pests and vectors. The use of environmental risk assessment before introduction of non-native control agents is essential. 
A bacterial toxin (Bti) produced by Bacillus thuringiensis israelensis is commonly used in a variety of habitats against a multitude of species of mosquitoes in several countries (Lacey, 2007). Factors that influence the larvicidal activity of Bti include species of mosquito and their respective feeding strategies, rate of ingestion, age and density of larvae, habitat factors, formulation factors (type of formulation, toxin content, how effectively the material reaches the target) and means of application and frequency of treatments. Bti is reported to be very specific to mosquitoes and therefore only the target organisms are affected (Lacey, 2007). However, unwanted side-effects have been reported for Bti and there is discussion as to whether this is a true biological treatment.

With mosquito vectors, environmental control, including reduction of oviposition sites, and larvicide application are important aspects of mosquito control. Many vectors, e.g. several species of both Culicoides and Culex, are habitat generalists breeding in a range of moist microhabitats including man-made possibilities such as irrigation channels, drainage pipes, dung heaps, flooded cellars, etc. (Purse at al., 2008; Reiter, 2008). Such spots may be virtual factories for vectors. Effective sewage disposal and the elimination of standing polluted water may limit the risk by reducing population of Culicoides (Purse et al., 2008) and Culex mosquitoes (Reiter, 2008).

Integrated pest or vector management is an approach combining biological control agents, environmental management, personal protection and the judicious use of pesticides, etc. Here it is necessary to carefully consider the transmission cycle and then focus on several methods to reduce the opportunities for host-vector interaction and to reduce the proportion of infectious vectors (Ginsberg, 2001; Peter et al., 2005). For example, keeping stock indoors at times of high vector activity may reduce transmission of an infection. Vaccination of animals or humans, when an effective vaccine is available, may reduce the proportion of infectious vectors. In the best case scenario vaccination of a reservoir species may eliminate the infection from a vector population. However for e.g. BTV, where 24 different serotypes have been identified, a multivalent vaccine protecting against several of these serotypes would be complicated and costly to produce (Gould and Higgs, 2009). However, when wildlife species act as reservoirs vaccination may be more complicated. Integrated vector management, when successful, may counteract pesticideresistant vectors, enhance the withdrawal of chemicals and minimise the usage of pesticides.

For adaptation to $\mathrm{CC}$ it is vital that more effective, sustainable approaches for vector control are developed. Such methods may be based on genetics, spread of sterile males, etc. In addition, public education and preventive advice are important in protecting humans from VBD. Protective clothing, insect repellents and mosquito nets may be efficient for protecting humans from bites, when available and affordable.

\section{Conclusions}

Nature is on the move in response to climate change. A great deal of change lies ahead, with a negative global impact predicted on food and feed production. Shortage of water will become an increasing problem. At present ecosystem change and biodiversity decline is a fact. However, there are many other changes that also influence ecosystem health and these may even be of higher importance than climate change. New health problems will emerge, affecting domestic animals, wildlife and humans. A special focus is needed on vector-borne diseases; Blue tongue, West Nile fever and Lyme borreleosis are concrete examples. Their presence and epidemiology are largely dependent on ecosystem changes and since they involve wildlife, vector-borne diseases may be very hard to control. Heat stress may cause suppressed production and lowered reproduction performance in domestic animals. Another effect of heat stress is a suppressed immune response, which may result in infectious diseases being more easily acquired. However, positive effects of climate change may also be seen, especially in the temperate and cold northern latitudes. These may come from a prolonged vegetation period, leading to improved feed production and a prolonged grazing period for domestic animals.

We have to consider - and handle - both known and unknown health effects. To develop adaptation strategies concerning health effects, a multidisciplinary and deep understanding is needed of the complex and dynamic interactions between climate change, ecosystem health, wildlife, domestic animals and humans. Increasing knowledge 
concerning infectious diseases can be used to forecast, and in the best case prevent, some effects of climate change. World-wide, intensive and effective surveillance of domestic and wild animal health is essential and efficient international networking should be compulsory. Early detection and action, before an infectious disease has been widely spread, are essential for successful control and eradication. So for some diseases and in some cases, action must be taken without complete knowledge. Last but not least, vector control efforts must be further developed and the reliance on chemical control must be reduced. 
de Balogh, K.K., Schouten, M.C. and Lipman, L.J. 2002. [Bioterrorism: the role of veterinarians in detection and prevention]. In: Tijdschr. Diergeneeskd. 127:616-619.

Gill, D.M. 1982. Bacterial toxins: a table of lethal amounts. In: Microbiol Rev. 46:86-94.

Grabenstein, J.D. 2003. Anthrax vaccine: a review. In: Immunol. Allergy Clin. North Am. 23:713-730.

Green, U., Kremer, J.H., Zillmer, M. and Moldaenke, C. 2003. Detection of chemical threat agents in drinking water by an early warning realtime biomonitor. In: Environ Toxicol. 18:368-374.

Hartung, J. 1992. [Environmental hygiene tasks of the veterinarian in practice]. In: Dtsch. Tierarztl. Wochenschr. 99:279-281.

Higgins, J.A., Nasarabadi, S., Karns, J.S., Shelton, D.R., Cooper, M., Gbakima, A. and Koopman, R. P. 2003. A handheld real time thermal cycler for bacterial pathogen detection. In: Biosens. Bioelectron. 18:1115-1123.

Hugh-Jones, M. 2003. Surveillance for emergencies. In: $J$ Vet. Med. Educ. 30:148-151.

Isolauri, E. 2001. Probiotics in human disease. In: Am. J Clin. Nutr. 73:1142S-1146S

Khan, A. S., Swerdlow, D. L. and Juranek, D. D. 2001. Precautions against biological and chemical terrorism directed at food and water supplies. In: Public Health Rep. 116:3-14.

McAvin, J. C., Morton, M. M., Roudabush, R. M., Atchley, D. H. and Hickman, J. R. 2004. Identification of Francisella tularensis using real-time fluorescence polymerase chain reaction. In: Mil. Med. 169:330-333. Meinhardt, P. L. 2004. Water and Bioterrorism: Preparing for the Potential Threat to U.S. Water Supplies and Public Health. In: Annu. Rev. Public Health.

Mossel, D. A. 1990. [The veterinarian active in the field of veterinary public health, towards the year 2000]. In: Tijdschr. Diergeneeskd. 115:115-124

Ried, K. 2004. Gastrointestinal health. The role of pro- and pre-biotics in standard foods. In: Aust. Fam. Physician 33:253-255.

Rose, J.B. 2002. Water quality security. In: Environ. Sci. Technol. 36:246A-250A.

Schechter, R. and Arnon, S.S. 2000. Extreme potency of botulinum toxin. In: Lancet 355:237-238.

White, F. 2002. Water: life force or instrument of war? In: Lancet 360 Suppl:29-30.

\section{Chapter 38}

ACIA (Arctic Climate Impact Assessment). 2005. Scientific report: Impact of a warming arctic. Cambridge University Press, Cambridge, UK, pp. 1042

Albihn, A. 2009. Infectious Waste Management. In Moselio Schaechter (Ed.) Encyclopedia of Microbiology. Oxford: Elsevier, pp. 500512.

Al-Katanani , Y.M., Paula-Lopes, F.F. and Hansen, P.J.. 2002. Effect of Season and Exposure to Heat Stress on Oocyte Competence in Holstein Cows. In: Journal of Dairy Science, 85 (2), pp. 390-396.

Bale, J.S., Van Lenteren, J.C. and Bigler, F. 2008. Biological control and sustainable food production. In: Philosophical transactions of the Royal Society of London. Series B, 363, pp. 761-776.
Blitvich, B.J. 2008. Transmission dynamics and changing epidemiology of West Nile virus. In: Anim Health Res Rev. 9, pp71-86.

Brugger, K. and Rubel, F. 2009. Simulation of climate-change scenarios to explain Usutu-virus dynamics in Austria. In: Prev. Vet. Med, (88), pp. 24-31

Cameron, R.D. and Blackshaw, A.W. 1980. The effect of elevated ambient temperature on spermatogenesis in the boar. In: J. Reprod. Fertility, 59, pp. 173-179.

CDC Centers for Disease Control and prevention. 2004, Apr 23. Eradication of Malaria in the United States (1949-1951) http://www. cdc.gov/malaria/history/eradication_us.htm]

CDC Centre for Disease Control and Prevention. 2008. West Nile virus activity-United States, 2007. In: MMWR Morb Mortal Wkly Rep 2008;57, pp. 720-723.

Cavestany, D., El-Wishy, A.B. and Foote, R.H. 1985. Effect of season and high environmental temperature on fertility of Holstein cattle. In: J. Dairy Sci. 68, pp. 1471-1478.

Cazelles, B. and Hales, S. 2006. Infectious diseases, climate influences, and non-stationarity. In: PloS Medicine. 3, pp.328 http://www.plosmedicine.org

Collier, R.J., Doelger, S.G., Head, H.H., Thatcher, W.W. and Wilcox C.J. 1982. Effects of Heat Stress during Pregnancy on Maternal Hormone Concentrations, Calf Birth Weight and Postpartum Milk Yield of Holstein Cows. In: J. Anim. Sci. 54, pp. 309-319.

Daniel, M., Danielová, V., Kríz, B., Jirsa, A. and Nozicka, J. 2003. Shift of the tick Ixodes ricinus and tick borne encephalitis to higher altitudes in central Europe. In: Eur J Clin Microbiol Infect Dis. 22, pp. 327-328

de La Rocque, S., Rioux, J. A. and Slingenbergh, J. 2008. Climate change: effects on animal disease systems and implications for surveillance and control. In: Rev Sci Tech 27(2): 339-54.

Dobson, A., Cattadori, I., Holt, R.D., Ostfeld, R.S., Kessing, F., Krichbaum, K., Rohr, J.R., Perkins, S.E. and Hudson, P.J. 2006. Sacred cows and sympathetic squirrel: the importance of biological diversity to human health. In: PloS Medicine. 3, pp.231 http://www. plosmedicine.org

Dohm, D.J., O'Guinn, M.L. and Turell, M.J. 2002. Effect of environmental temperature on the ability of Culex pipiens (Diptera: Culicidae) to transmit West Nile virus. In: J Med Entomol. 39, pp. $221-25$.

Dufour, B., Moutou, F., Hattenberger, A.M. and Rodhain, F. 2008. Global change: impact, management, risk approach and health measures - the case of Europe. In: De La Rocque, S., Hendrickx, G. and Morand, S. (eds.) Climate change: impact on the epidemiology and control of animal diseases. Rev. Sci. Tech. Off. Int. Epiz., 27 (2), pp. 529-550.

Ebel, G.D., Rochlin, I., Longacker, J. and Kramer, L.D. 2005. Culex restuans (Diptera: Culicidae) relative abundance and vector competence for West Nile Virus. In: J Med Entomol. 42, pp. 838-43.

Epstein, P.R. 1995. Emerging diseases and ecosystem instabilities: new threats to public health. In: Am J Publ Health. 85, pp. 168-172.

Epstein, P.R. 2002. Biodiversity, climate change, and emerging infectious diseases. In: Alonso Aguirre, A., Ostfeld, R.S., Tabor, G.M., House, C. and Pearl, M.C. (eds.) Conservation medicine. Ecological health in practice. New York: Oxford Univ. Press pp27-39. 
FAO. 2008. Food and Agriculture Organization of the United Nations, Declaration of the high-level conference on world food security: The challenges of climate change and bioenergy. Rome, Italy, June 2008. www.fao.org

Feachem, R.G., Bradley, D.J., Garelick, H. and Mara, D. 1983. Sanitation and disease. Health aspects of excreta and wastewater management. World bank studies in Water Supply and Sanitation 3, Bath, GB: Pitman Press.

Flint, A.P.F. and Woolliams, J.A. 2008. Precision animal breeding. In: Phil. Trans. R. Soc. B. 363, pp. 573-590.

Gajadhar, A.A. and Allen, J.R. 2004. Factors contributing to the public health and economic importance of waterborne zoonotic parasites. In: Vet. Parasitol. 126, pp. 3-14.

Gammon, D.W. 2007. Public safety aspects of pyrethroid insecticidesused in West Nile Virus-carrying mosquito control. In: Pest Manag. Sci. 63, pp. 625-627.

Garcia-Isperto, I., Lopez-Gatius, F., Santolaria, P., Yaniz, J.L., Nogareda, C., Lopez-Bejar, M. and De Rensis, F. 2006. Relationship between heatstress during the peri-implantation period and early fetal loss in dairy cattle. In: Theriogenology. 65, pp. 799-807.

Gilad, E., Meidan, R., Berman, A., Graber, Y. and Wolfenson, D. 1993. Effect of heat stress on tonic and GnRH-induced gonadotrophin secretion in relation to concentration of oestradiol in plasma in cyclic cows. In: J. Reprod. Fertil. 99, pp. 315-321.

Ginsberg, H.S. 2001. Integrated pest management and allocation of control efforts for vector-borne diseases. In: $J$ Vector Ecol. 26, pp. 32-38.

Gould, E.A. and Higgs, S. 2009. Impact of climate change and other factors on emerging arbovirus diseases. In: Trans. R. Soc. Trop. Med. Hyg.103, pp. 109-121.

Gray, J.S., Dautel, H., Estrada-Pena, A., Kahl, O. and Lindgren, E. 2009. Effects of climate change on ticks and tick-borne diseases in Europe. In: Interdiscip Perspect Infect Dis. 59, 3232.

Gubler, D.J. 1998. Resurgent vector-borne diseases as a global health problem. In: Emerg Infect Dis. 4, pp. 442-450.

Gubler, D.J., Reiter, P., Ebi, K.L., Yap, W., Nasci, R. and Patz, J.A. 2001. Climate variability and change in the United States: potential impacts on vector- and rodent-borne diseases. In: Environ. Health Persp. 109, pp. 223-233.

Gwasdauskas, F.C., Thatcher, W.W. and Wilcox, C.J. 1973. Physiological, environmental and hormonal factors at insemination which may affect conception. In: J. Dairy Sci. 56, pp. 873-877.

Hales, S., Kovats, S. and Woodward, A. 2006. What El Niño can tell us about human health and global climate change. In: Global change \& human health $1 \mathrm{pp} 66-77$.

Hamer, G.L., Kitron, U.D., Brawn, J.D., Loss S.R., Ruiz, M.O., Goldberg, T.L. and Walker, E.D. 2008. Culex pipiens (Diptera: Culicidae): a bridge vector of West Nile virus to humans. In: $J$ Med Entomol. 45, pp. 125-128.

Harrington, L.C, Scott, T.W. and Lerdthusnee, K. et al. 2005. Dispersal of the dengue vector Aedes aegypti within and between rural communities. In: Am J Trop Med Hyg. 72, pp209-220.

Hartelt, K., Pluta, S. and Ochme, R. 2008. Spread of ticks and tickborne diseases in Germany due to global warming. In: Parasitol Res. 103, pp109-116.
Hayes, C.G. 2001. West Nile virus: Uganda, 1937, to New York City, 1999. In: Ann N Y Acad Sci. 951 pp25-37.

Hubalek, Z. 2004. An annotated checklist of pathogenic microorganisms associated with migratory birds. In: $J$ Wildl Dis. 40, pp. 639659.

Hubalek, Z., Zeman, P., Halouzka, J. and Juricova Z. et al. 2004. [Article in Czech] Antibodies against mosquito-borne viruses in human population of an area of Central Bohemia affected by the flood of 2002. In: Epidemiol Mikrobiol Imunol. 53, pp. 112-120.

Hubalek, Z. 2009. Epidemiology of Lyme Borreliosis. In: Curr Probl Dermatol. 37, pp31-50.

Huynh, T.T.T., Aarnink, A.J.A., Verstegen, M.W.A., Gerrits, W.J.J., Heetkamp, M.J.W., Kemps, B. and Canh, T.T. 2005. Effects of increasing temperatures on physiological changes in pigs at different relative humidities. In: J. Anim. Sci. 83 pp1385-1396.

IPCC. 2007. Climate change: Impacts, adaptation and vulnerability. Working group II contribution to the Intergovernmental Panel on Climate Change, Fourth assessment report. Cambridge University Press. http://www.ipcc.ch/ipccreports/ar4-syr.htm

Jones, C.J. and Kitron, U.D. 2000. Populations of Ixodes scapularis (Acari: Ixodidae) are modulated by drought at a Lyme disease focus in Illinois. In: J Med Entomol. 37, pp. 408-415.

Jordan, E.R. 2003. Effects of heat stress on reproduction. In: J. Dairy Sci. 86, pp104-114.

Kinde, H., Hietala, S.K., Bolin, C.A. and Dowe, J.T. 1996. Leptospiral abortion in horses following a flooding incident. In: Equine Vet $J$. 28, pp327-330.

Kriz, B. 1998. Infectious disease consequences of the massive 1997 summer floods in the Czech Republic. Working Group Paper. EHRO 020502/12.

Kutz, SJ, Hoberg, EP, Polley, L. 2001. A new lungworm in muskoxen: an exploration in arctic parasitology. In: TRENDS in Parasitology. 6, pp276-280.

Lacey, L.A. 2007. Bacillus thuringiensis serovariety israeliensis and Bacillus sphaericus for mosquito control. In: J. American Mosquito Control Association, 23, 2 (Suppl), pp133 - 163.

Lindgren, E., Tälleklint, L. and Polfeldt, T. 2000. Impact of climatic change on the northern latitude limit and population density of the disease-transmitting European tick, Ixodes ricinus. In: Environ Health Perspect. 108, pp119-123.

LoGiudice, K, Ostfeld, RS, Schmidt, KA, Keesing, F. 2003. The ecology of infectious disease: effects of host diversity and community composition on Lyme disease risk. In: Proc Natl Acad Sci U S A. 100, pp567-571.

Lovejoy, T. 2008. Climate change and biodiversity. In: De La Rocque, S., Hendrickx, G. and Morand, S. (eds.) Climate change: impact on the epidemiology and control of animal diseases. Rev. Sci. Tech. Off. Int. Epiz., 27 (2), pp. 331-338.

Marcogliese, D.J. 2008. The impact of climate change on the parasites and infectious diseases of aquatic animals. In: De La Rocque, S., Hendrickx, G. and Morand, S. (eds.) Climate change: impact on the epidemiology and control of animal diseases. Rev. Sci. Tech. Off. Int. Epiz., 27 (2), pp. 467-484.

Mas-Coma, S., Valero, M.A. and Bargues, M.D. 2008. Effect of climate change on animal and zoonotic helminthiases. In: De La Rocque, S., Hendrickx, G. and Morand, S. (eds.) Climate change: impact on the 
epidemiology and control of animal diseases. Rev. Sci. Tech. Off. Int. Epiz., 27, pp. 443-458.

McCabe, G.J. and Bunnell, J.E. 2004. Precipitation and the occurrence of lyme disease in the northeastern United States. In: Vector Borne Zoonotic Dis. 4, pp143-48.

McMichael, A.J., Woodruff, R.E. and Hales, S. 2006. Climate change and human health: present and future risks. In: Lancet. 367, pp. 859-69.

Mehlhorn, H., Walldorf, V., Klimpel, S. and Schmahl, G. 2008. Outbreak of bluetongue disease (BTD) in Germany and the danger for Europe. In: Parasitol Res. 103 Suppl 1, pp79-86.

Mintiens, K., Meroc, E., Faes, C., Abrahantes, J.C, Hendrickx, G., Staubach, C., Gerbier, G., Elbers, A.R., Aerts, M. and De Clercq, K. 2008. Impact of human interventions on the spread of bluetongue virus serotype 8 during the 2006 epidemic in north-western Europe. In: Prev Vet Med. 87, pp. 145-61.

Mitcherlich, E. and Marth, E.H. 1983. Microbial survival in the environment. Berlin: Springer Verlag

Moore, C.G., Francy, D.B., Eliason, D.A. and Monath, T.P. 1988. Aedes albopictus in the United States: rapid spread of a potential disease vector. In: J Am Mosq Control Assoc. 4, pp356-61.

Morton, J.M, Tranter, W.P, Mayer, D.G, Jonsson, N.N. 2007. Effects of environmental heat on conception rates in lactating dairy cows: critical periods of exposure. In: J. Dairy Sci. 90, pp. 2271-2278.

Ogden, N.H., Bigras-Poulin, M., Hanincova, K., Maarouf, A., O'Callaghan, C.J. and Kurtenbach, K. 2008. Projected effects of climate change on tick phenology and fitness of pathogens transmitted by the North American tick Ixodes scapularis. In: J. Theor. Biol. 254, pp621-632.

Ostfeld, R.S., Canham, C.D., Oggenfuss, K., Winchcombe, R.J. and Keesing, F. 2006. Climate, deer, rodents, and acorns as determinants of variation in lyme-disease risk. In: PLoS Biol. 4, pp. 145.

Parmesan, C. 2006. Ecological and evolutionary responses to recent climate change. In: Annual Review of Ecology, Evolution and Systematics. 37 pp. 637-669.

Patz, J.A., Epstein, P.R., Burke, T.A. and Balbus, J.M. 1996 . Global climate change and emerging infectious diseases. In: JAMA 275, pp. 217-223.

Pennington, J.A., Albright, J.L., Diekman, M.A. and Callahan, C.J. 1985. Sexual activity of Holstein cows: seasonal effects. In: J. Dary Sci. 68, pp. 3023-3030.

Peter, R.J., Van den Bossche, P., Penzhorn, B.L. and Sharp, B. 2005. Tick, fly, and mosquito control-lessons from the past, solutions for the future. In: Vet Parasitol. 132, pp. 205-215.

Purse, B.V., Brown, H.E., Harrup, L., Mertens, P.P.C. and Rogers, D.J. 2008. Invasion of Bluetongue and other orbivirus infections into Europe: the role of biological and climatic processes. In: De La Rocque, S., Hendrickx, G. and Morand, S. (eds.) Climate change: impact on the epidemiology and control of animal diseases. Rev. Sci. Tech. Off. Int. Epiz., 27 (2), pp. 427-442.

Quiniou, N.S., Dubois, S. and Noblet, J. 2000. Voluntary feed intake and feeding behaviour of group-housed growing pigs are affected by ambient temperature and body weight. In: Livestock Production Science. 63, pp. 245-253.

Randolph, S.E. 2008. Dynamics of tick-borne disease systems: minor role of recent climate change. In: Rev. Sci. Tech. Off. Int. Epiz., $27(2)$, pp. 367-81.
Reisen, W.K., Fang, Y. and Martinez, V.M. 2005. Avian host and mosquito (Dipthera: Culicidae) vector competence determine the efficiency of West Nile and St. Louis encephalitis virus transmission. In: J Med Entomol. 42, pp. 367-375.

Reiter, P. 2008. Climate change and mosquito-borne disease: knowing the horse before hitching the cart. In: De La Rocque, S., Hendrickx, G. and Morand, S. (eds.) Climate change: impact on the epidemiology and control of animal diseases. Rev. Sci. Tech. Off. Int. Epiz., 27 (2), pp. 383-398.

Rogers, D.J. and Randolph, S.E. 2006. Climate change and vectorborne diseases. In: Adv Parasitol. 62, pp. 345-381.

Roth, Z., Arav, A., Bor, A., Zeron, Y., Braw-Tal, R. and Wolfenson, D. 2001. Improvement of quality of oocytes collected in the autumn by enhanced removal of impaired follicles from previously heatstressed cows. In: Reproduction, 122, pp737-744.

Ruiz-Fons, F., Reyes-Garcia, A.R., Alcaide, V. and Gortazar, C. 2008. Spatial and temporal evolution of bluetongue virus in wild ruminants, Spain. In: Emerg Infect Dis. 14, pp. 951-53.

Rummukainen, M. and Källén, E. 2009. Ny klimatvetenskap 20062009. Kommissionen för hållbar utveckling, Regeringskansliet, Stockholm, Sweden.

Saegerman, C., Berkvens, D. and Mellor, P.S. 2008. Bluetongue epidemiology in the European Union. In: Emerg Infect Dis.14, pp. 539544.

Sartori, R., Sartor-Bergfelt, R., Mertens, S.A., Guenther, J.N., Parrish, J.J. and Wiltbank, M.C. 2002. Fertilization and early embryonic development in heifers and lactating cows in summer and lactating dry cows in winter. In: J. Dairy Sci. 85, pp. 2803-2812.

Sellers, R.F. 1992. Weather, Culicoides, and the distribution and spread of bluetongue and African horse sickness virus. In: Walton, T.E. and Osburn, B.I. (eds.) Blutongue, African Horse Sickness and related Orbiviruses, Proc. Sec. Internat. Symp, CRC Press, pp. 284-290.

Setchell, B.P. 2006. The effects of heat on the testes of mammals. Internat. Symp. Anim Biol Reprod, Nov. 15-18, Brazil. V.3, n.2. pp. 81-91.

Schmidt, K.A. and Ostfeld, R.S. 2001. Biodiversity and the dilution effect in disease ecology. In: Ecology, 82(3), pp. 609-619.

Steinfeld, H., Gerber, P., Wassenaar, T., Castel, V., Rosales, M. and de Haan, C. 2006. Livestock's long shadow - environmental issues and options. FAO, Rom. http://www.virtualcentre.org/en/library/key_ pub/longshad/A0701E00.htm

Suriyasomboon, A., Lundeheim, N., Kunavongkrit, A. and Einarsson, S. 2006. Effect of temperature and humidity on reproductive performance of crossbred sows in Thailand. In: Theriogenology. 65 , pp. 606-628.

SOU. 2007. Sverige inför klimatförändringarna - hot och möjligheter. Slutbetänkande Klimat- och Sårbarhetsutredningen. SOU 2007:60. http://www.regeringen.se/sb/d/8704/a/89334

Takken, W. and Knols, B.G.J. 2007. Emerging pests and vector-borne diseases in Europe. Wageningen, the Netherlands: Wageningen Acadmic Publishers.

Thom, E.C. 1959. The discomfort index. Weatherwise. 12, pp. 57-59.

USDC-ESSA. 1970. Livestock hot weather stress. Central regional operations manual letter 70-28. Environmental Sciences Services Admin., U.S. Dep. Commerce. Silver Spring, M.D. In: Hahn, G.L. and Nienaber, J.A. (eds.) Engineeing and management practices 
to ameliorate livestock heat stress. USDA-ARS U.S. Meat Animal Research Center. Kansas City, MO, USA.

van Dijk, J., David, G.P., Baird, G. and Morgan, E.R. 2008. Back to the future: Developing hypotheses on the effects of climate change on ovine parasitic gastroenteritis from historical data. In: Vet. Parasit. 158 , pp. $73-84$.

Veterinary Laboratories Agencies (VLA). 2007. Surveillance report - Wildlife, 9, 3, England http://www.defra.gov.uk/corporate/vla/science/science-end-survrep-qtly.htm

WHO. 2004. The vector-borne human infections of Europe - their distribution and burden on public health. WHO Regional Office for Europe. pp144.

Wittmann, E.J. and Baylis, M. 2000. Climate change: Effects on Culicoides-transmitted viruses and implications for the UK. In: The Vet. J. 160, pp107-117.

Wolfenson, D., Thatcher, W., Badinga, L., Savio, D., Meidan, R., Lew, B.J., Braw-Tal, R. and Berman, A. 1995. Effect of heat stress on follicular development during the oestrous cycle in lactating dairy cattle. In: Biol. Reprod. 52, pp. 1106-1113.

Wood, E.N. and Lysons, R.J. 1988. Financial benefit from the eradication of swine dysentery. In: Vet.Rec. A, 122, (12) pp. 277-279.

Vrbova, L. and Middleton, D. 2006. Descriptive epidemiology of Lyme disease in Ontario: 1999-2004. In: Can Commun Dis Rep. 32, pp247-57.

Ytrehus, B., Bretten, T., Bergsjö, B. and Isaksen, K. 2008. Fatal pneumonia epizootic in musk ox (Ovibus moschatus) in a period of extraordinary wether conditions. In: EcoHealth., pp. 213-223.

Zimmer, J.Y., Haubruge, E., Francis, F., Bortels, J., Joie, E., Simonon, G., De Deken, R., De Deken, G., Deblauwe, I., Madder, M., Fassotte, C., Cors, R., Defrance, T., Saegerman, C., Thiry, E., Mignon, B., Paternostre, J., Losson, B. and Kirschvink, N. 2008. Distribution of potential bluetongue vectors on Belgium farms. In: Vet Rec.162, pp. 700 .

\section{Further Reading:}

Epstein, P.R. 2001. West Nile virus and the climate. In: J Urban Health. 78, pp. 367-371

Parmesan, C. and Yohe, G. 2003. A globally coherent fingerprint of climate change impacts across natural systems. In: Nature 421 pp 37 42

Patz, J.A., Campbell-Lendrum, D., Holloway, T. and Foley, J.A. 2005. Impact of regional climate change on human health. In: Nature. 438, pp. 310-317.

Root, T.L., Price, J.T., Hall, K.R., Schneider, S.H., Rosenzweig, C. and Pounds, J.A. 2003. Fingerprints of global warming on wild animals and plants. In: Nature, 421, pp57-60. 